University of Nebraska - Lincoln

DigitalCommons@University of Nebraska - Lincoln

Publications, Agencies and Staff of the U.S.

Department of Commerce

U.S. Department of Commerce

2012

Coupling planktonic ecosystem and fisheries food web models for a pelagic ecosystem: Description and validation for the subarctic Pacific

\author{
Kelly A. Kearney \\ Princeton University, kkearney@princeton.edu \\ Charles Stock \\ Geophysical Fluid Dynamics Laboratory, Charles.Stock@noaa.gov \\ Kerim Aydin \\ Alaska Fisheries Science Center, Kerim.Aydin@noaa.gov \\ Jorge L. Sarmiento \\ Princeton University, jls@princeton.edu
}

Follow this and additional works at: https://digitalcommons.unl.edu/usdeptcommercepub

Part of the Environmental Sciences Commons

Kearney, Kelly A.; Stock, Charles; Aydin, Kerim; and Sarmiento, Jorge L., "Coupling planktonic ecosystem and fisheries food web models for a pelagic ecosystem: Description and validation for the subarctic Pacific" (2012). Publications, Agencies and Staff of the U.S. Department of Commerce. 343.

https://digitalcommons.unl.edu/usdeptcommercepub/343

This Article is brought to you for free and open access by the U.S. Department of Commerce at DigitalCommons@University of Nebraska - Lincoln. It has been accepted for inclusion in Publications, Agencies and Staff of the U.S. Department of Commerce by an authorized administrator of DigitalCommons@University of Nebraska - Lincoln. 


\title{
Coupling planktonic ecosystem and fisheries food web models for a pelagic ecosystem: Description and validation for the subarctic Pacific
}

\author{
Kelly A. Kearney a,*, Charles Stock ${ }^{b}$, Kerim Aydin ${ }^{d}$, Jorge L. Sarmiento ${ }^{c}$ \\ a Department of Geosciences, Princeton University, Princeton, NJ 08544, United States \\ ${ }^{b}$ Geophysical Fluid Dynamics Laboratory, NOAA, 201 Forrestal Road, Princeton, NJ 08540, United States \\ c Program in Atmospheric and Ocean Sciences, Princeton University, Princeton, NJ 08544, United States \\ d Alaska Fisheries Science Center, NOAA, 7600 Sand Point Way N.E., Building 4, Seattle, WA 98115, United States
}

\section{A R T I C L E I N F O}

\section{Article history:}

Received 15 December 2011

Received in revised form 3 April 2012

Accepted 7 April 2012

\section{Keywords:}

Ecosystem model

North Pacific Ocean

NEMURO

Ecopath with Ecosim

End-to-end model

food web

\begin{abstract}
A B S T R A C T
We provide a modeling framework that fully couples a one-dimensional physical mixed layer model, a biogeochemical model, and an upper trophic level fisheries model. For validation purposes, the model has been parameterized for the pelagic Eastern Pacific Subarctic Gyre ecosystem. This paper presents a thorough description of the model itself, as well as an ensemble-based parameterization process that allows the model to incorporate the high level of uncertainty associated with many upper trophic level predator-prey processes. Through a series of model architecture experiments, we demonstrate that the use of a consistent functional response for all predator-prey interactions, as well as the use of densitydependent mortality rates for planktonic functional groups, are important factors in reproducing annual and seasonal observations. We present the results of a 50-year climatological simulation, which demonstrates that under contemporary physical forcing, the model is capable of reproducing long-term seasonal dynamics in primary production and biogeochemical cycling, while maintaining steady-state coexistence of upper trophic level functional groups at levels consistent with observations.
\end{abstract}

(c) 2012 Elsevier B.V. All rights reserved.

\section{Introduction}

In the past decade, fisheries management efforts have placed increased emphasis on ecosystem-based management, where the interactions between a target stock species and its physical and biological environment are considered in addition to sustainability of the stock itself (e.g. Link, 2010). At the same time, globalscale climate models that historically focused only on physical and biogeochemical variables are increasingly incorporating biological variables (Denman et al., 2007). With these shifts, the historical separation between climate modeling and fisheries modeling is closing, with increased interest in the concept of end-to-end models, i.e. models that incorporate dynamics from physics to top predators (Travers et al., 2007; Fulton, 2010).

In their review of over fifty different fisheries models, Keyl and Wolff (2008) demonstrated that the incorporation of environmental and climate variability in almost all cases increased the predictive power of the model. They also noted that in many cases, the use of a climate index, such as the Pacific Decadal Oscillation

\footnotetext{
* Corresponding author. Tel.: +1 3057244998.

E-mail addresses: kkearney@princeton.edu (K.A. Kearney), Charles.Stock@noaa.gov (C. Stock), Kerim.Aydin@noaa.gov (K. Aydin), jls@princeton.edu (J.L. Sarmiento).
}

(PDO) or North Atlantic Oscillation (NAO), had more predictive power than any single local environmental variable, such as sea surface temperature, due to the collective nature of a climate index in incorporating many different physical changes. However, while climate indices can demonstrate correlation between climate variability and ecosystem dynamics, they fail to provide a mechanistic link between the physical and biogeochemical changes and higher trophic level dynamics. Such mechanistic linkages are particularly essential for reliable projections of climate change impacts as the baseline upon which empirical relationships are based changes (Stock et al., 2011).

A variety of modeling methodologies have been introduced in recent years to resolve the mechanistic connections between environmental variability and upper trophic level dynamics (Travers et al., 2007; Plaganyi, 2007; Fulton, 2010). Some of these couple biogeochemical-physical models to species-focused individualbased or bioenergetics models, e.g. the SEAPODYM model for tuna (Lehodey et al., 2008) and the NEMURO.FISH model for herring and saury (Megrey et al., 2007). While this allows for detailed investigation of the effect of the environment on the target fish species, most models of this type do not explicitly resolve ecosystem dynamics between the modeled fish species and its predators and competitors, or take into account community reorganization that could result from changing climate. Other efforts have added lower trophic level forcing with modeled or observed primary production 


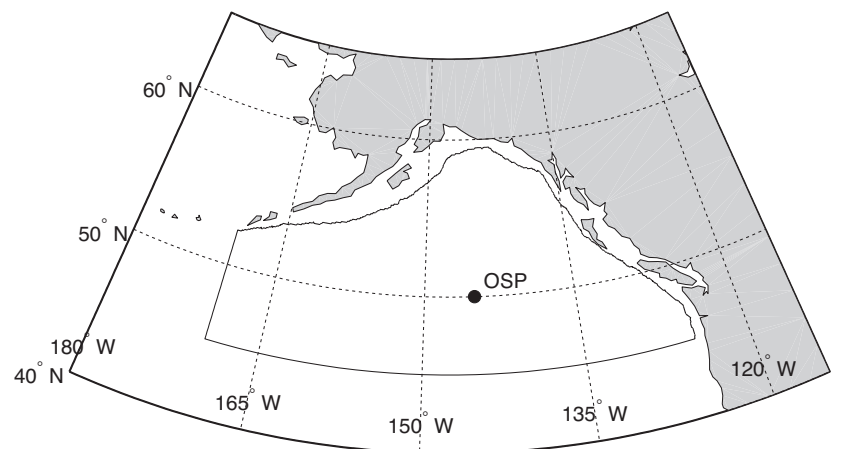

Fig. 1. The Eastern Subarctic Gyre region, for the purposes of this study, is defined as the region north of $40^{\circ} \mathrm{N}$ and east of $170^{\circ} \mathrm{W}$, excluding the continental shelf. The location of Ocean Station Papa (OSP) is also shown.

to established food web models, such as with Ecopath with Ecosim (Christensen and Walters, 2004) and ATLANTIS (Fulton et al., 2004, 2004); this allows resolution of feedbacks between various functional groups in an ecosystem in response to climate variations, but does not allow two-way feedback of these effects back down to the level of primary production or biogeochemistry. Size-based efforts, such as APECOSM (Maury, 2010) provide a simple framework to look at flows through the entire food chain, though they lack resolution of individual species or functional groups.

Here, we introduce a modeling structure that combines a fisheries food web model, a biogeochemical model, and a physical model into a fully coupled end-to-end ecosystem model. The goal of this framework is to represent the primary trophic interactions of an ecosystem and their response to both bottom-up climate variability and top-down predation changes in a fully integrated manner. The challenge in constructing a model of this type derives from the high level of uncertainty associated with measurements and calculations of upper trophic level feeding and growth parameters, as well as the sensitivity of lower trophic level plankton dynamics to mortality rates that are altered by direct modeling of upper trophic level predation (Yoshie et al., 2007). Furthermore, differences in modeling approaches that traditionally have been used for plankton ecosystems versus fisheries food webs can exacerbate these issues by introducing subtle dynamical differences that lead to significant changes over long time scales. We will describe an approach that addresses these challenges, producing an ensemble of simulations capable of reproducing long-term seasonal dynamics in primary production and biogeochemical cycling, while maintaining steady-state coexistence of upper trophic level functional groups at levels consistent with observations under contemporary physical forcing. Critical aspects of the coupling between plankton ecosystem and fisheries food web models that are required to achieve such robust simulations are identified through a series of sensitivity tests.

While the modeling framework proposed here is generic to any ecosystem, for this study we have tailored the parameterization to the Eastern Subarctic Gyre of the North Pacific (Fig. 1). This region is an important foraging ground for a variety of epipelagic species (Brodeur et al., 1999), and a rearing and growth area for commercially important Pacific salmon (Aydin et al., 2005). The climate of this location is heavily influenced by variations in the Aleutian Low Pressure system, resulting in decadal scale variability in physical properties such as sea surface temperature, precipitation, downwelling, and stratification (Mantua et al., 1997; Francis et al., 1998). Numerous studies have demonstrated corresponding population changes in the biology at multiple trophic levels, including that of phytoplankton (Polovina et al., 1995), zooplankton (Brodeur and Ware, 1992), and salmon (Beamish and Bouillon, 1993). Because the region demonstrates this decadal-scale climate variability and supports commercially important fisheries, and previous studies have led to a relatively high number of both biogeochemical and fisheries datasets, it makes a convenient testbed for an end-to-end ecosystem model.

\section{Methods}

\subsection{The water column ecosystem model framework}

The end-to-end ecosystem model framework developed here is based on three different components: a one-dimensional physical mixed layer model component, a lower trophic level biogeochemical component based on the NEMURO model (Kishi et al., 2007), and an upper trophic level food web component based on the Ecopath with Ecosim model (Christensen and Walters, 2004). The three components are fully coupled, allowing the simulation of feedbacks between the physical environment and all levels of the food chain.

\subsubsection{The physical model}

The physical model used in this study simulates the seasonal evolution of a one-dimensional water column, resolved vertically and forced at the surface by winds, shortwave radiation, and air and dew point temperatures. Simulations were run under climatological conditions at a single location (Ocean Station Papa, $50^{\circ} \mathrm{N}$, $145^{\circ} \mathrm{W}$ ). Because advective processes are minimal in the gyre, a one-dimensional model can capture the predominant processes at this location (Denman and Miyake, 1973), and analysis of the major water masses in the region indicates similar salinity, temperature, and nutrient profiles throughout the Alaska Gyre region (north of the Subarctic Current and excluding the shelf region) (Wong et al., 2002). Therefore, for our purposes, we consider this one-dimensional water column to be representative of the entire gyre region.

Salinity is relaxed towards a depth- and time-resolved timeseries on a 7-day timescale, which allows salinity profiles to respond to storm events (2-3 days) but preserves the seasonal evolution of the salinity field. Observed winds are translated to surface wind stresses using the bulk formulae of Large and Pond (1981). Latent and sensible heat fluxes are calculated from the wind speed, air-sea temperature difference, and dew point temperature using the bulk formulae of Friehe and Schmitt (1976). Longwave radiation losses are calculated using the Efimova formula, per Simpson and Paulson (1979). We assume $45 \%$ of the incoming shortwave radiation is photosynthetically available, with a background attenuation of $0.15 \mathrm{~m}^{-1}$; self-shading by phytoplankton is applied within the primary production calculations but does not feed back to the physical state variables. Mixing is calculated following the Mellor-Yamada 2.5 algorithm with a background diffusivity of $1.0 \times 10^{-4} \mathrm{~m}^{2} \mathrm{~s}^{-1}$, over a water column of $500 \mathrm{~m}$ depth with a vertical grid spacing of $10 \mathrm{~m}$. See Appendix A for further details of the physical model formulation.

\subsubsection{The lower trophic level biogeochemical model}

The NEMURO (North Pacific Ecosystem Model for Understanding Regional Oceanography) model is a nutrient-phytoplankton-zooplankton model developed to study the interactions between the planktonic communities of the North Pacific and their environment. The model tracks 11 state variables: small and large phytoplankton; small, large, and predatory zooplankton; nitrogen in the forms of particulate and dissolved organic nitrogen (PON and DON, respectively), nitrate $\left(\mathrm{NO}_{3}\right)$, and ammonium $\left(\mathrm{NH}_{4}\right)$; and silica as particulate opal and silicic acid $\left(\mathrm{Si}(\mathrm{OH})_{4}\right)$ (Kishi et al., 2007). Since its origin, many variations on the NEMURO model have been developed (Werner et al., 2007; Kishi et al., 2010). These include spatial variations ranging 
Table 1

Ecopath variables (Table 2, Aydin et al., 2003). For units, $M=$ mass, $A=$ area, and $\mathrm{T}=$ time.

\begin{tabular}{|c|c|c|c|}
\hline Parameter & Description & Units & Source \\
\hline B & Biomass & $\mathrm{MA}^{-1}$ & $\begin{array}{l}\text { Survey estimates, sampling programs, } \\
\text { stock assessments }\end{array}$ \\
\hline $\mathrm{P} / \mathrm{B}$ & Production per unit biomass & $\mathrm{T}^{-1}$ & $\begin{array}{l}\text { Mortality rates, growth rates, } \\
\text { bioenergetics models }\end{array}$ \\
\hline $\mathrm{Q} / \mathrm{B}$ & Consumption per unit biomass & $\mathrm{T}^{-1}$ & $\begin{array}{l}\text { Bioenergetics models, gut content } \\
\text { analysis }\end{array}$ \\
\hline DC & $\begin{array}{l}\text { Diet composition, i.e. fraction of predator's diet composed } \\
\text { of each prey }\end{array}$ & & Gut content analysis \\
\hline Y & Fisheries catch & $\mathrm{MA}^{-1} \mathrm{~T}^{-1}$ & Fisheries statistics \\
\hline $\mathrm{BA}$ & Biomass accumulation & $\mathrm{MA}^{-1} \mathrm{~T}^{-1}$ & Biomass trend data \\
\hline E & Net migration & $\mathrm{MA}^{-1} \mathrm{~T}^{-1}$ & Migration studies \\
\hline $\mathrm{EE}$ & $\begin{array}{l}\text { Ecotrophic efficiency, i.e. the fraction of a group's } \\
\text { production that is passed up the food chain. A value of } 1 \\
\text { implies that all loss is due to predation; a value of } 0 \\
\text { implies that the group has no predators and all loss is due } \\
\text { to non-predatory processes, such as old age or disease. }\end{array}$ & & $\begin{array}{l}\text { Estimated by Ecopath or set at a } \\
\text { standard level to estimate biomass }\end{array}$ \\
\hline GE & Gross growth efficiency. $G E=P / Q$ & & \\
\hline GS & Fraction of ingested food that is not assimilated. & & \\
\hline
\end{tabular}

from surface-layer only (Kishi et al., 2007) or one-dimensional water column physics (Fujii et al., 2007) to three-dimensional regional models (Aita et al., 2007); versions that incorporate the carbon cycle (Fujii et al., 2007); and NEMURO.FISH, which adds a bioenergetic component for certain fish species (Megrey et al., 2007).

In this study, we use a version of the NEMURO model based on Kishi et al. (2007) with a few modifications. First, we replaced the Steele light curve (Steele, 1962) with a Platt curve (Platt and Jassby, 1976), reducing the effect of photoinhibition at higher light levels. We raised the maximum grazing rate of small zooplankton from 0.4 day $^{-1}$ to 0.8 day $^{-1}$ to be consistent with observed allometric relationships for zooplankton (Hansen et al., 1997). In order to reflect the difference in sinking behavior between small phytoplankton, which usually have low export- and $f$-ratios, and larger phytoplankton whose blooms sink and contribute to export out of the surface layer, we rerouted half of the small phytoplankton nonpredatory losses from the particulate sink (PON) to the dissolved nitrogen pools ( $\mathrm{DON}$ and $\mathrm{NH}_{4}$ ). We also rerouted the egestion of microzooplankton to the dissolved nitrogen pools to be consistent with the observed importance of microzooplankton egestion to dissolved organic matter (Nagata, 2000). Finally, we lowered the silica dissolution rate to 1 /(23 day), in line with globally averaged surface observations (Van Cappellen et al., 2002).

In addition to these parameter adjustments, we introduced a simple iron cycle to the model. In previous versions of NEMURO, iron limitation has been approximated through parameterization by reducing the growth rates of iron-limited phytoplankton (Denman and Pena, 1999). The Eastern Subarctic Gyre is a highnutrient, low-chlorophyll region where iron plays a key role in limiting growth, and we found we were unable to create a simulation that produced realistic large phytoplankton (diatom) blooms while also maintaining surface nutrients at observed levels without explicitly including the effects of iron limitation. Therefore, we added additional iron dynamics following the model of Fiechter et al. (2009). This model adds an iron limitation term to the alreadyexisting nitrogen, silica, and light limitation terms that moderate gross primary production; iron limitation is based on the iron to carbon ratio within phytoplankton cells, and allows for luxury iron uptake during iron-rich conditions.

In addition to its incorporation into the fully coupled model described below, this version of NEMURO was used for comparison and parameterization purposes. Table 5 includes the full list of parameters used when running NEMURO in its standalone form. In this form, it is run within the physical model described above but not coupled to any upper trophic level dynamics. Loss to higher trophic levels is approximated through a quadratic mortality closure term.

\subsubsection{The upper trophic level model}

The Ecopath with Ecosim model has become a widely used tool in fisheries science for constructing food web models. The Ecopath idea, originally described by Polovina (1984) and later developed into a more comprehensive software package with additional components for time-dynamic (Ecosim) and spatially explicit (Ecospace) simulations (Christensen and Walters, 2004), uses the concept of ecosystem mass balance in order to consolidate a wide range of fisheries-based data into a coherent picture of biomass or energy fluxes between various ecosystem components. The massbalance model consists of a set of linear equations describing the flux of biomass into and out of each functional group in the food web. Depending on the focus of an individual study, functional groups can refer to specific species or more general groups of species that share certain growth and diet characteristics, as well as detrital pools and fishing gears associated with the ecosystem. The primary equation for the Ecopath model states that fluxes into a functional group must balance fluxes out of the group or contribute to a known accumulation of biomass:

$$
\begin{aligned}
\underbrace{B_{i}\left(\frac{P}{B}\right)_{i}}_{\text {production }}= & \underbrace{\sum_{j}\left(B_{j} \cdot\left(\frac{Q}{B}\right)_{j} \cdot D C_{i j}\right)}_{\text {predation mortality }}+\underbrace{Y_{i}}_{\substack{\text { fisheries } \\
\text { mortality }}}+\underbrace{E_{i}}_{\substack{\text { net } \\
\text { emigration }}} \\
& +\underbrace{P_{i} \cdot\left(1-E E_{i}\right)}_{\text {other mortality }}+\underbrace{B A_{i}}_{\text {biomass accumulation }}
\end{aligned}
$$

where $i$ refers to an individual functional group and $j$ refers to the functional groups that prey on it. Table 1 describes these variables and their typical data sources. Note that the inclusion of the biomass accumulation term $(B A)$ means that the system does not necessarily need to be in steady state, though often the use of data spanning a longer time period requires an assumption of stability. By incorporating as much data as possible for the various groups, the Ecopath mass-balance algorithm is able to create a snapshot of the standing stock of biomass pools and the network of fluxes between these pools such that all mass within the ecosystem is accounted for in a manner consistent with the observations available for the system.

By using the Ecopath-derived biomass values as initial conditions, and the network flux values as parameter constraints on the functional process equations defining each flux between functional groups, a time-dynamic model can be created. This is the concept 


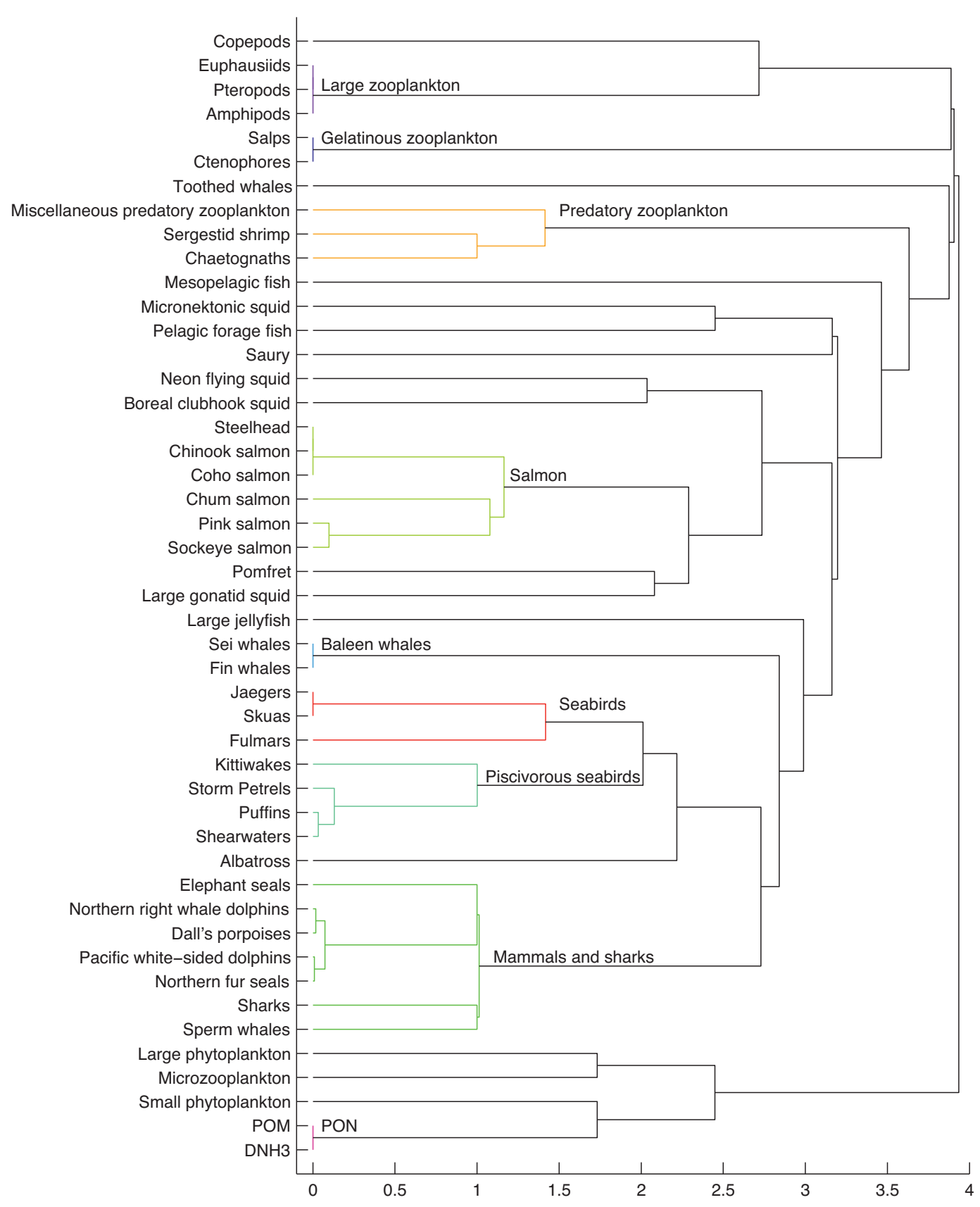

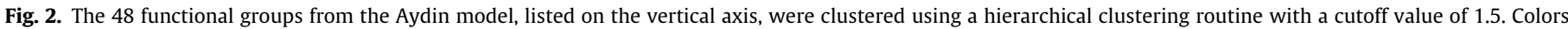
indicate groups that were combined in the simplified version of the food web, with simplified group names to the right of each.

behind Ecosim, a second part of the Ecopath with Ecosim software package. While not used explicitly, the Ecosim idea forms the basis for predator/prey-related processes in the end-to-end water column ecosystem biological model used in this study.

To construct the Ecopath food web necessary for deriving these initial conditions, we began with a previously published Ecopath model that was developed through series of workshops by the North Pacific Marine Science Organization (PICES) Basin Ecosystem (BASS) Task Team (Aydin et al., 2003); this food web included 48 functional groups, so we refer to it hereafter as the Aydin-48 model. The Aydin-48 model included a large number of managed stocks with very similar trophic characteristics, while the emphasis of this study is primarily on the main trophic interactions within the ecosystem. Therefore, we reduced the number of functional groups in the ecosystem while still maintaining the major energy pathways through the food web. The simplification of the food web was performed using MATLAB ${ }^{\circledR}$ 's agglomerative hierarchical clustering routine. Our similarity metric for the clustering process included diet composition, using shared prey and predator groups as the main descriptive parameters, along with level of primary production and trophic level to maintain the basic trophic hierarchy in the clustered results, reducing the original 48 groups to 24 groups (Fig. 2). Parameters for the new food web were derived from the Aydin-48 model parameters; the simplified food web biomass values consist of the sum of the biomasses of the contributing groups, and the remaining Ecopath input variables $(\mathrm{Q} / \mathrm{B}, \mathrm{P} / \mathrm{B}, \mathrm{EE}, \mathrm{GE}, \mathrm{BA}$, and GS) were calculated by averaging the values of the contributing groups' parameters, weighted by the biomass contribution of 


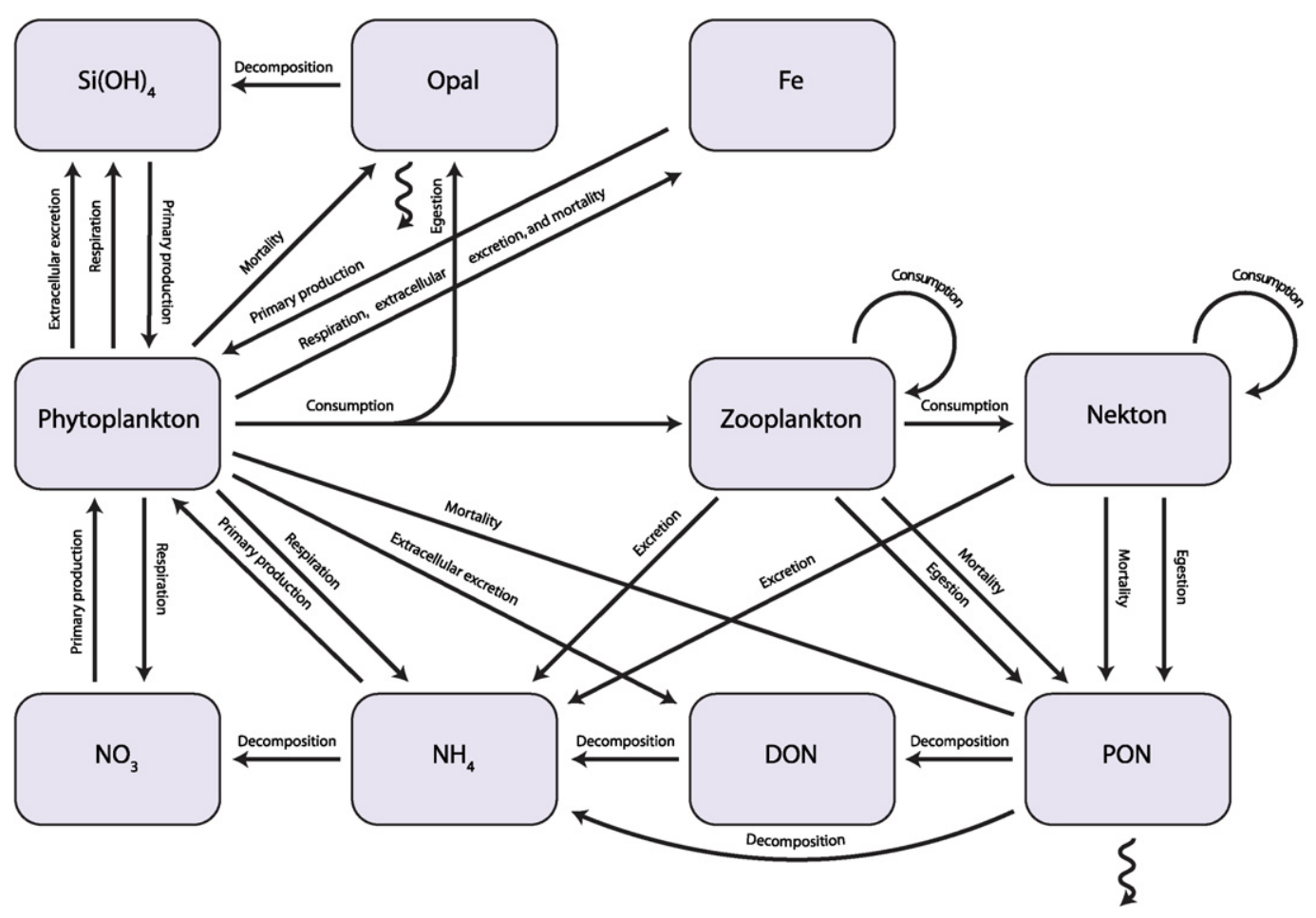

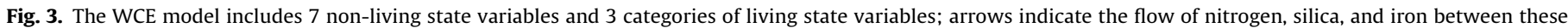

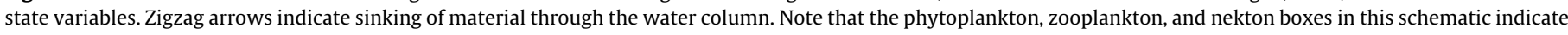

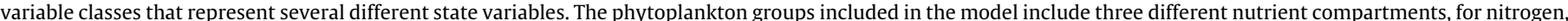

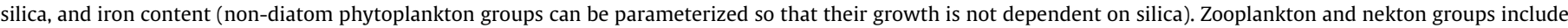

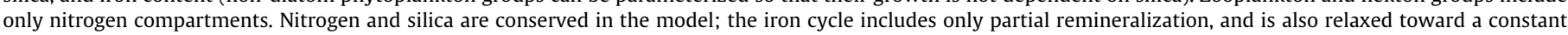
profile to approximate advective and airborne sources, and therefore is not conserved.

each subgroup. We verified that the resulting simplified food web maintained the same flux of biomass to each trophic level as the original 48-group food web, and also subjected it to a variety of food web diagnostics following Link (2010b).

In the Aydin-48 model, Ecopath parameters for the phytoplankton and zooplankton groups were derived from an early version of the NEMURO model (Eslinger et al., 2000). To maintain internal consistency with our slightly modified version of NEMURO, the parameter ranges for the five functional groups in the Eastern Subarctic Gyre food web that correspond to the five living NEMURO state variables were adjusted to reflect the annual averages seen in standalone runs of our modified NEMURO model described in Section 2.1.2.

Three of the Ecopath Aydin-48 input parameter types, B, P/B, and $\mathrm{Q} / \mathrm{B}$, were published along with data pedigrees that indicated the quality of the data source from which each was derived (Aydin et al., 2003). The pedigree values range from 0 to 1 , and correspond to a confidence interval of the point estimate as a fraction of that point estimate. These pedigree values were incorporated into our simplified version of the food web, resulting in parameter ranges for each of these three input parameters (Table 7).

Only a small subset of the resulting Ecopath input variable parameter space leads to a balanced Ecopath model, i.e. a model in which all ecotrophic efficiency (EE) values fall in the range of $0-1$. An ecotrophic efficiency value outside of this range implies that the system requires an outside sink or source in order to account for all biomass fluxes. Following the ideas of Aydin et al. (2007), we produced a set of 500 food webs whose parameters had been selected randomly from within the parameter space defined in Table 7 and which met the ecotrophic efficiency balance requirements; the result was an intra-model ensemble of potential food web parameters that incorporated the uncertainty in the upper trophic level data. For this study, the results of 50 of these balanced simulations will be shown.

\subsection{Coupling the model components}

The coupled biogeochemical-lower trophic level-upper trophic level model, referred to hereafter as the water column ecosystem (WCE) model, merges aspects of both the NEMURO model and an Ecopath-derived food web model to create an end-to-end ecosystem model. The nutrient state variables were drawn from the NEMURO model. The remaining living state variables are classified into three types: phytoplankton (P), zooplankton $(Z)$, or nekton (K) (Fig. 3). The designation of living functional groups as either planktonic or nektonic reflects both their relationship to the physical model and their interactions with other functional groups. The planktonic label refers to any group whose movement is strongly influenced by the movement of the water in which they reside; these groups are resolved with depth, can feed only on functional groups occupying the same depth layer as themselves, and are subject to mixing via advection and diffusion in the same manner as all physical tracers. The nektonic label refers to all other living organisms, including those that do not live in the water but feed on marine organisms (such as birds); these groups are not subject to any mixing, and they feed on the integrated sum over depth of their prey groups.

The plankton/nekton distinction can be difficult to make since nearly all organisms are generally capable of some movement relative to advective and mixing processes. In this context, it is used to distinguish those functional groups whose foraging distance over a single model time step $(3 \mathrm{~h})$ is comparable to or less than the physical model resolution $(10 \mathrm{~m})$ and therefore limited to a single grid cell, and whose distribution in the water column can be important 


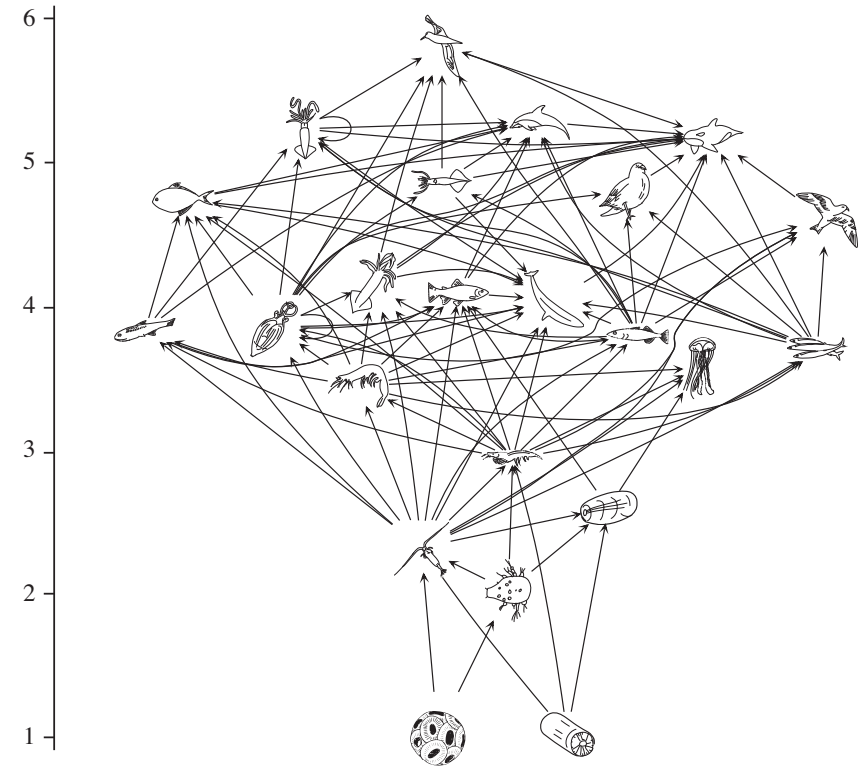

Fig. 4. The food web used for this study incorporates 23 living functional groups. The axis to the left indicates the trophic level of each group, following the Ecopath definition where trophic level of a consumer is equal to 1 plus the weighted average of its prey's trophic levels.

to their feeding, versus those whose foraging covers multiple grid cells and is not strongly depth-dependent. Therefore, for the purposes of the WCE model, zooplankton are designated as planktonic even if they are capable of vertical migration; vertical movement can be parameterized through the sinking/rising rate parameter in the physical model if necessary to capture the dynamics of a particular ecosystem. The impact of these assumptions will be discussed in Section 3.1.

For the fully coupled model, 23 of the 24 functional groups from the Ecopath food webs described in Section 2.1.3 were used as state variables, with the detrital group being discarded in favor of the more detailed nutrient cycling from the NEMURO model. These 23 groups encompass 2 phytoplankton groups, 5 zooplankton groups, and 16 nekton groups (Fig. 4, Table 2). Both phytoplankton groups and three of the zooplankton groups in the Aydin model fill the same functional roles as the five plankton groups in the NEMURO model.

Fig. 3 displays a schematic of the processes linking the state variables to each other. A brief description of each process type can be found in Table 3, with detailed process equations in Appendix B. Most of these processes were exclusive to a single parent model component; gross primary production, phytoplankton respiration, extracellular excretion, and decomposition are only explicitly modeled in NEMURO, while non-depth-resolved consumption is included only in Ecopath. Egestion and excretion by consumers are modeled identically in both models as a fraction of consumption. However, planktonic consumption and non-predatory mortality differ in several fundamental ways between the two parent models:

1 Resolution: NEMURO models all fluxes volumetrically, while Ecopath models are typically built using depth-integrated units.

2 Grazing/predation functional response: NEMURO uses a thresholded Ivlev functional response for zooplankton grazing and predation, while Ecopath with Ecosim models use a foraging arena functional response (Walters et al., 1997) for all predatorprey consumption, including that between planktonic groups.

3 Effect of temperature on rates: In NEMURO, almost all rate processes, including grazing, predation, and mortality, are affected by temperature, increasing exponentially with increasing temperature. The standard implementation of Ecopath with Ecosim does not include any direct effects of temperature (though time forcing and trophic mediation timeseries can be used to approximate this effect).

4 Mortality: In NEMURO, non-predatory mortality is proportional to the square of the biomass, while Ecopath with Ecosim uses a linear mortality function.

When building the WCE model, decisions regarding how to treat these differences proved very important in determining the stability and realism of the final model. A set of experiments using different coupling strategies was conducted to identify the key features essential for robust simulations on climate time scales. A list of the different model architectures we tested can be found in Table 4. We started with a "brute force" baseline coupling between the NEMURO and fisheries food web models (Section 2.2.1), resulting in a model that contains inconsistencies between formulations of closely interacting groups. We then took steps to increase the internal consistency of the planktonic and nektonic formulations, and to evaluate the necessity of additional mortality regimes for plankton and nekton groups (Sections 2.2.2 and 2.2.3).

\subsubsection{The baseline case}

We started with an Ecosim-style model and replaced all fluxes that overlapped with NEMURO, namely grazing and predation by microzooplankton (small zooplankton ZS in NEMURO), copepods (large zooplankton ZL), and large zooplankton (predatory zooplankton ZP), as well as net primary production, with the corresponding process functions from NEMURO. We opted to use the Ecosim-derived linear form for mortality for all groups, on the assumption that a linear form would be more applicable to a system where all predator-prey relationships are explicitly resolved rather than being modeled implicitly through quadratic loss terms.

\subsubsection{Consistent feeding formulations across planktonic groups}

For its grazing and predation processes, the NEMURO model uses a thresholded Ivlev curve of the form

$I=m\left(1-\exp \left(-\lambda\left(B-B_{\text {thresh }}\right)\right)\right)$

where $m$ is a maximum grazing rate, $\lambda$ is the Ivlev constant, $B_{\text {thresh }}$ is the threshold prey concentration for grazing to occur, $B$ is the biomass of prey, and $I$ is the ingestion rate of prey per unit predator. The upper trophic level model, on the other hand, uses the foraging arena functional response (Walters et al., 1997) as modified by Aydin:

$\operatorname{ConI}_{i j}=Q_{i j}^{*}\left(\frac{X_{i j} \cdot\left(\text { Bint }_{j} / B_{j}^{*}\right)}{X_{i j}-1+\left(\text { Bint }_{j} / B_{j}^{*}\right)}\right)\left(\frac{D_{i j} \cdot\left(\text { Bint }_{i} / B_{i}^{*}\right)^{\theta_{i j}}}{D_{i j}-1+\left(\text { Bint }_{i} / B_{i}^{*}\right)^{\theta_{i j}}}\right)$

where the subscripts $i$ and $j$ represent the prey and predator groups, respectively. Note that Eq. (3) calculates the total consumption flux from prey to predator, such that the ingestion rate (similar to $I$ in Eq. (2)) would be equal to $\left(\operatorname{ConI}_{i j}\right) /\left(B_{j}\right)$. The parameters in this functional response are derived from the Ecopath model for the food web being modeled: $Q^{*}$ is the mass-balanced depth-integrated consumption between two groups, and $B^{*}$ is the mass-balanced depth-integrated biomass of a group. The remaining parameters in Eq. (3), i.e., $X, D$, and $\theta$, are non-dimensional parameters that control the shape of the functional response curve.

Qualitatively, the Ivlev and foraging arena formulations differ in several ways (Fig. 5). In NEMURO, the maximum grazing rate parameter $(m)$ is temperature-dependent, while the consumption parameter in Ecosim $\left(Q_{i j}^{*}\right)$ is fixed over time. The Ivlev formulation calculates an ingestion rate that is independent of the predator biomass, while the foraging arena ingestion rate can be modulated by both the prey and predator biomasses, with the parameter $X$ 
Table 2

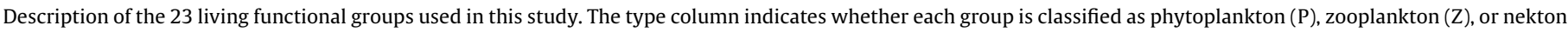
(K).

\begin{tabular}{|c|c|c|c|c|}
\hline Index & Name & Type & Symbol & Description \\
\hline 1 & Albatross & K & & Albatross \\
\hline 2 & Mammals and sharks & K & & $\begin{array}{l}\text { Northern elephant seals, northern fur seals, sperm whales, Dall's porpoises, Pacific } \\
\text { white sided dolphins, northern right whale dolphins, sharks (primarily salmon) }\end{array}$ \\
\hline 3 & Neon flying squid & K & & Neon flying squid \\
\hline 4 & Orcas & K & & Orcas \\
\hline 5 & Boreal clubhook squid & K & & Boreal clubhook squid \\
\hline 6 & Seabirds & K & & Skuas, jaegars, fulmars, \\
\hline 7 & Pomfret & K & & Pacific pomfret \\
\hline 8 & Piscivorous seabirds & K & & Shearwaters, storm petrals, kittiwakes, puffins \\
\hline 8 & Large gonatid squid & K & & Familty Gonatidae \\
\hline 10 & Salmon & K & & Coho, pink, sockeye, chum, and chinook salmon, steelhead \\
\hline 11 & Baleen whales & K & & Fin whales, sei whales \\
\hline 12 & Micronektonic squid & K & & Juvenile squid, primarily gonatids \\
\hline 13 & Mesopelagic fish & K & & Primarily Myctiphidae \\
\hline 14 & Pelagic forage fish & K & & Mainly sticklebacks \\
\hline 15 & Saury & K & & Pacific saury \\
\hline 16 & Large jellyfish & K & & Large jellyfish \\
\hline 17 & Predatory zooplankton & & & $\begin{array}{l}\text { Sergestid shrimp, chaetognaths, and miscellaneous predatory } \\
\text { zooplankton (mainly larvaceans and polychaetes) }\end{array}$ \\
\hline 18 & Large zooplankton & Z & & Euphausiids, amphipods, and pteropods, equivalent to ZP in the NEMURO model \\
\hline 19 & Gelatinous zooplankton & Z & & Salps and ctenophores \\
\hline 20 & Copepods & Z & & Copepods, equivalent to ZL in the NEMURO model \\
\hline 21 & Microzooplankton & Z & & $\begin{array}{l}\text { Meroplanktonic larvae and copepod nauplii, }<200 u m \text {, equivalent to ZS in the } \\
\text { NEMURO model }\end{array}$ \\
\hline 22 & Small phytoplankton & $\mathrm{P}$ & & Small phytoplankton, equivalent to PS in the NEMURO model \\
\hline 23 & Large phytoplankton & $\mathrm{P}$ & & Large phytoplankton, primarily diatoms, equivalent to PL in the NEMURO model \\
\hline
\end{tabular}

defining the strength of the predator-related term. As $X$ approaches infinity, the predator-related portion of Eq. (3) disappears, creating a linear relationship between grazing rate and number of predators for a constant amount of prey. However, if $X$ is set to a lower number, the grazing rate versus predator density relationship saturates. A lower value of $X$ can be used to approximate predator avoidance behaviors of prey, which effectively make only a small portion of a prey population vulnerable to predation (Walters et al., 1997). With
$X$ equal to infinity, the foraging arena functional response simplifies to a classic Holling Type $2(\theta=1$, Eq. (4)) or Holling Type $3(\theta=2$, Eq. (5)) functional response:

$\frac{\operatorname{Con}_{i j}}{B_{j}}=\frac{m B_{i}}{k+B_{i}}: \quad m=\frac{Q_{i j}^{*} D_{i j}}{B_{j}^{*}}, k=B_{i}^{*}\left(D_{i j}-1\right)$ 
Table 3

WCE model process variables.

\begin{tabular}{|c|c|c|c|}
\hline Process & Variable & Parent component & Description \\
\hline Gross primary production & $G p p$ & NEMURO & $\begin{array}{l}\text { Function of light, temperature, and nutrient concentration, following Kishi } \\
\text { et al. (2007)and Fiechter et al. (2009) }\end{array}$ \\
\hline Respiration & Res & NEMURO & $\begin{array}{l}\text { First-order relationship to biomass, with Q10 = } 2 \text { temperature effect, } \\
\text { following Kishi et al. (2007) }\end{array}$ \\
\hline Extracellular excretion & Ex & NEMURO & $\begin{array}{l}\text { First-order relationship to gross primary production, following Kishi et al. } \\
\text { (2007) }\end{array}$ \\
\hline Planktonic consumption & Con & NEMURO and Ecopath & $\begin{array}{l}\text { Variation of foraging arena functional response, parameterized where } \\
\text { applicable to mimic NEMURO Ivlev functional response, with Q10 = } 2 \\
\text { temperature effect }\end{array}$ \\
\hline Nektonic consumption & Con & Ecopath & Variation of foraging arena functional response \\
\hline Non-predatory mortality & Mor & NEMURO and Ecopath & Second-order relationship to biomass. \\
\hline Luxury iron uptake & Ufe & NEMURO & Follows Fiechter et al. (2009) \\
\hline Egestion & Ege & Ecopath & First-order relationship to consumption \\
\hline Excretion & Exc & Ecopath & First-order relationship to consumption \\
\hline Decomposition & Dec & NEMURO & $\begin{array}{l}\text { First-order relationship to concentration (i.e. biomass), with a Q10 = } 2 \\
\text { temperature effect }\end{array}$ \\
\hline
\end{tabular}

Table 4

We ran the water column ecosystem model with a variety of different formulations for the grazing, predation, and mortality fluxes.

\begin{tabular}{|c|c|c|}
\hline Run & Predator-prey functional response & Mortality formulation \\
\hline 1 (Baseline) & Ivlev curve for NEMURO-derived interactions, foraging arena for all others & Linear \\
\hline 2 & Modified foraging arena & Linear \\
\hline 3 & Ivlev curve for NEMURO-derived interactions, foraging arena for all others & Quadratic for plankton, linear for nekton \\
\hline 4 & Modified foraging arena & Quadratic for plankton, linear for nekton \\
\hline 5 & Ivlev curve for NEMURO-derived interactions, foraging arena for all others & Quadratic \\
\hline 6 & Modified foraging arena & Quadratic \\
\hline
\end{tabular}

$\frac{\operatorname{Con}_{i j}}{B_{j}}=\frac{m B_{i}^{2}}{k^{2}+B_{i}^{2}}: \quad m=\frac{Q_{i j}^{*} D_{i j}}{B_{j}^{*}}, k=B_{i}^{*} \sqrt{D_{i j}-1}$

Eqs. (4) and (5) are similar in shape to the Ivlev functional response, but with different treatment of ingestion rates at low prey densities.

Because the food web used in this study includes five planktonic groups that overlap with the NEMURO model and two that do not, the baseline version of the coupled model included a mix of these two functional responses. In order to achieve internal consistency, we wanted to choose a single functional response that is consistent with the Ecopath mass-balance formulation used to parameterize the rest of the model while also remaining consistent with the NEMURO formulation, which we know produces reasonable seasonal dynamics. To accomplish this, we modified the foraging arena functional response so that it could be applied to either nektonic or planktonic functional groups links. We first converted the Ecopath-derived parameters to volumetric terms to correspond to the units of planktonic groups within the WCE model. It is necessary to make an assumption about the depth distribution of planktonic organisms in order to convert the outputs of Ecopath into these per-volume quantities. The WCE model uses an average mixed layer depth, $M L D$, to make this conversion, so $Q^{\prime}=\left(Q^{*} / M L D\right)$ and $B^{\prime}=\left(B^{*} \mid M L D\right)$. The $M L D$ parameter is also used to set initial concentration profiles for all planktonic groups in the model.

To parameterize this response for planktonic groups, the NEMURO model zooplankton responses were used as the target functional response curves for all predator-prey interactions found in both the Eastern Subarctic Gyre ecosystem described above and the NEMURO model. The shape of the thresholded Ivlev curve can be best approximated by the grazing response used in the water column ecosystem model (Eq. (3)) when $X$ is set to infinity and $\theta$ to 2 , creating a sigmoidal Type 3 functional response (Fig. 5). The remaining parameter, $D$, is then calibrated so that the maximum grazing rates and half-saturation concentrations are as close as possible between the sigmoidal curve and Ivlev curve (Fig. 6).

For the final formulation, we also reintroduced the Q10 temperature effect from NEMURO by assuming that the mass-balanced values correspond to the rates under average mixed layer temperature conditions. This assured that all planktonic groups shared one consistent grazing functional response while also replicating the lower trophic level dynamics of the NEMURO model.

\subsubsection{Density dependent mortality}

In many biogeochemical models, a density-dependent mortality rate is used to capture predation losses from predators not explicitly resolved by the modeled system (e.g. Steele and Henderson, 1981). In the baseline scenario, we adopted a linear mortality rate because we had resolved all upper trophic level predation losses. However, density-dependent mortality can also arise for zooplankton due to egg cannibalism (Ohman and Hirche, 2001), and for phytoplankton due to aggregation (Thornton, 2002) and viral loss (Brussaard, 2004). Classic stock-recruitment theory also suggests that net reproduction rates for many fishes peak at an intermediate population, suggesting an increased mortality rate at higher population densities (Ricker, 1954). A nonlinear mortality rate may be needed to capture all of these processes, though the precise form is uncertain. Due to the lack of specific data to constrain our choice, we tested the model with both linear and quadratic mortality formulations.

\subsection{Simulations and model evaluation}

To evaluate the water column ecosystem model, we ran two series of simulation experiments. The first was a series of 20 -year simulations used to determine a robust coupling strategy. Once we had chosen a satisfactory architecture, we used a 50-year simulation to further validate the model against observations.

The 20-year simulations included six different sets of simulations, each using one of the model architectures outlined in Table 4. Shortwave radiation, air temperature, and wind speeds were extracted from the Coordinated Ocean-ice Reference Experiments (CORE) normal-year datasets (Large and Yeager, 2009). Dew point temperature was derived from the same dataset. A climatological salinity cycle was derived from the GECCO model's 


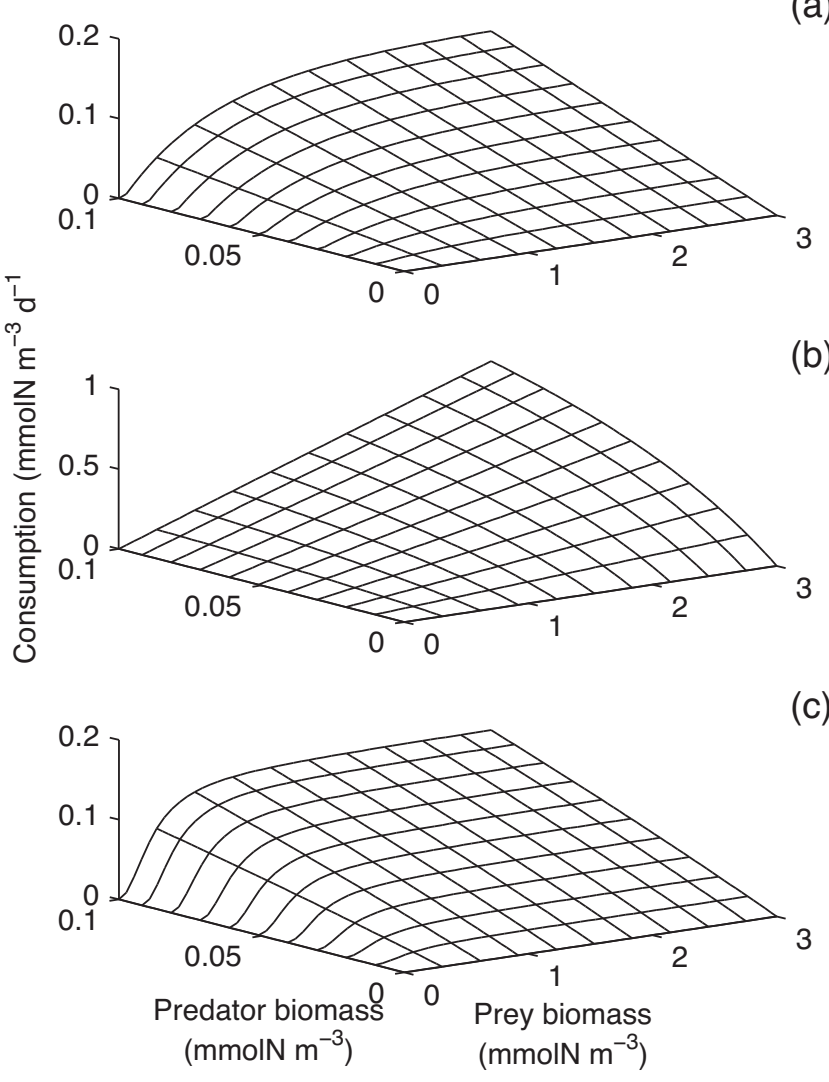

Fig. 5. Under their default parameter choices, the functional responses used in the NEMURO model and the Ecopath with Ecosim model differ greatly from each other. The Ivlev response varies linearly (Type 1 ) with increasing predator biomass and follows a Type 2 relationship with increasing prey biomass. The foraging arena response can vary between linear (high $X$ ) and Type 2 (low $X$ ) with increasing predator biomass, and linear (high $D$ ) and Type 2 (low $D, \theta=1$ ) or Type $3($ low $\mathrm{D}, \theta=2$ ) with increasing prey biomass. With careful choice of parameters, the two functional responses become quantitatively very similar. Shown here are (a) the thresholded Ivlev functional response for ZS grazing on PS in the NEMURO model, (b) the foraging arena functional response for microzooplankton grazing on small phytoplankton, with Ecosim default values $D=1000$ and $X=2$, and (c) the planktonic version of the foraging arena response used for WCE, where $X$ and $D$ have been calibrated so that the functional response has the same maximum grazing rate and half-saturation constant as the Ivlev response $(X=10, D=2.234)$.

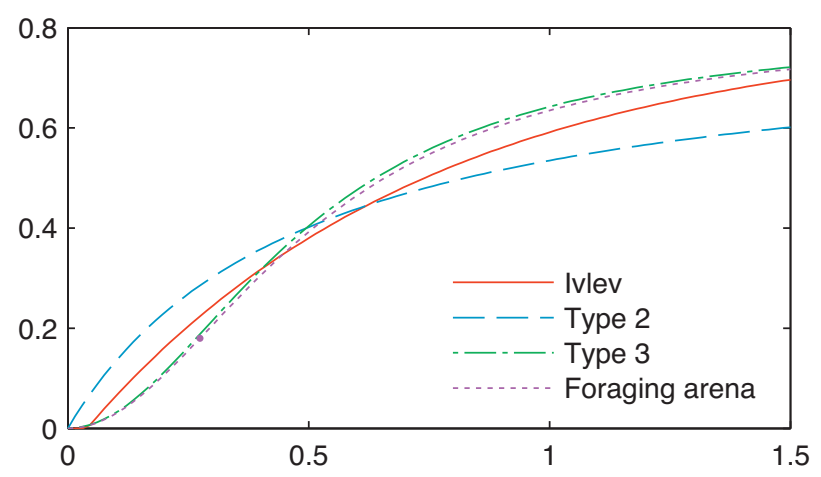

Fig. 6. The functional response for copepods grazing on large phytoplankton is shown here as an example of the functional response fitting process. Shown for reference are the NEMURO-derived Ivlev curve for this feeding link, as well as Holling Types 2 and 3 curves with identical half-saturation constants (i.e. $k=(\ln 2 / \gamma)$ ). The Ecopath mass balance constrains the foraging arena functional response to pass through the yearly averaged biomass vs. consumption rate, indicated by the purple dot, so we fit the parameter $D$ such that the resulting curve is as close as possible to the target Type 3 curve while respecting this constraint.
1950-2000 salinity product; initial profiles for both salinity and temperature were set to the climatological January profiles derived from the same product.

We quantified the success of each model architecture based on its ability to maintain yearly averaged biomass values for all functional groups within the uncertainty ranges used for the initial conditions over the entire 20-year simulation period. These initial biomass ranges reflect a compilation of the sparse observations of standing stock biomass available for the region, and therefore a model forced by average seasonal conditions should not deviate from these ranges.

Once we determined the best choice of model architecture, we further validated the model with a 50 -year simulation, again using climatological forcing, and compared the results against a broader suite of observations from the Eastern Subarctic Gyre region. The majority of these observations come from Ocean Station Papa. This location has been a site of regular physical and chemical sampling since the 1950s, thus allowing us to validate the lower trophic level biogeochemical results of the WCE model. We looked at several characteristics of the region in order to measure the skill of our model, including annual and seasonal macronutrient concentrations and drawdown, annual and seasonal primary production, and annual standing stock biomass for all living groups.

\section{Results}

\subsection{Choice of model architecture}

When running the baseline model simulation, we immediately encountered problems with competitive exclusion. For the particular ecosystem discussed here, the gelatinous zooplankton group biomass dropped well below the initial level within five years, with approximately $25 \%$ of the ensemble runs showing complete extinction of this group (Fig. 7, architecture 1). The exclusion resulted due to the overlapping prey preferences of the gelatinous zooplankton group (a non-NEMURO plankton group) and the large zooplankton group (a NEMURO-derived group). The difference between the numerical formulation for feeding behavior for the NEMURO- and non-NEMURO-based plankton groups granted a spurious competitive advantage to large zooplankton over gelatinous zooplankton. In this particular ecosystem, the consolidation of the food web via cluster analysis (Section 2.1.3) led to a minimal amount of overlap between diets of the modeled functional groups, and therefore the problem only manifested itself for one particular functional group. However, Ecopath models are often designed to resolve the dynamics of dozens of individually managed stocks that occupy very similar trophic niches. When applied to such a complex ecosystem, we would expect these spurious exclusions to increase.

Applying the modified foraging arena functional response consistently to all groups allowed all plankton groups to coexist (Fig. 7, architecture 2). However, even with the internally consistent functional responses, several plankton groups tended to wander outside their initial biomass ranges over the 20-year simulation period. While the yearly averaged biomass of the phytoplankton groups fell within the target ranges, the seasonal dynamics often departed from observations (not shown), with small phytoplankton showing an unrealistically large spring bloom along with a fall bloom not seen in observations in this location. The small phytoplankton blooms propagated up the food chain, with microzooplankton and large zooplankton increasing above their target ranges, while copepods and gelatinous zooplankton dropped below theirs.

Switching to a quadratic mortality function for all plankton groups produced much more realistic phytoplankton blooms and brought all zooplankton groups within their target ranges (Fig. 7, architecture 4). This may suggest that density-dependent mortality 


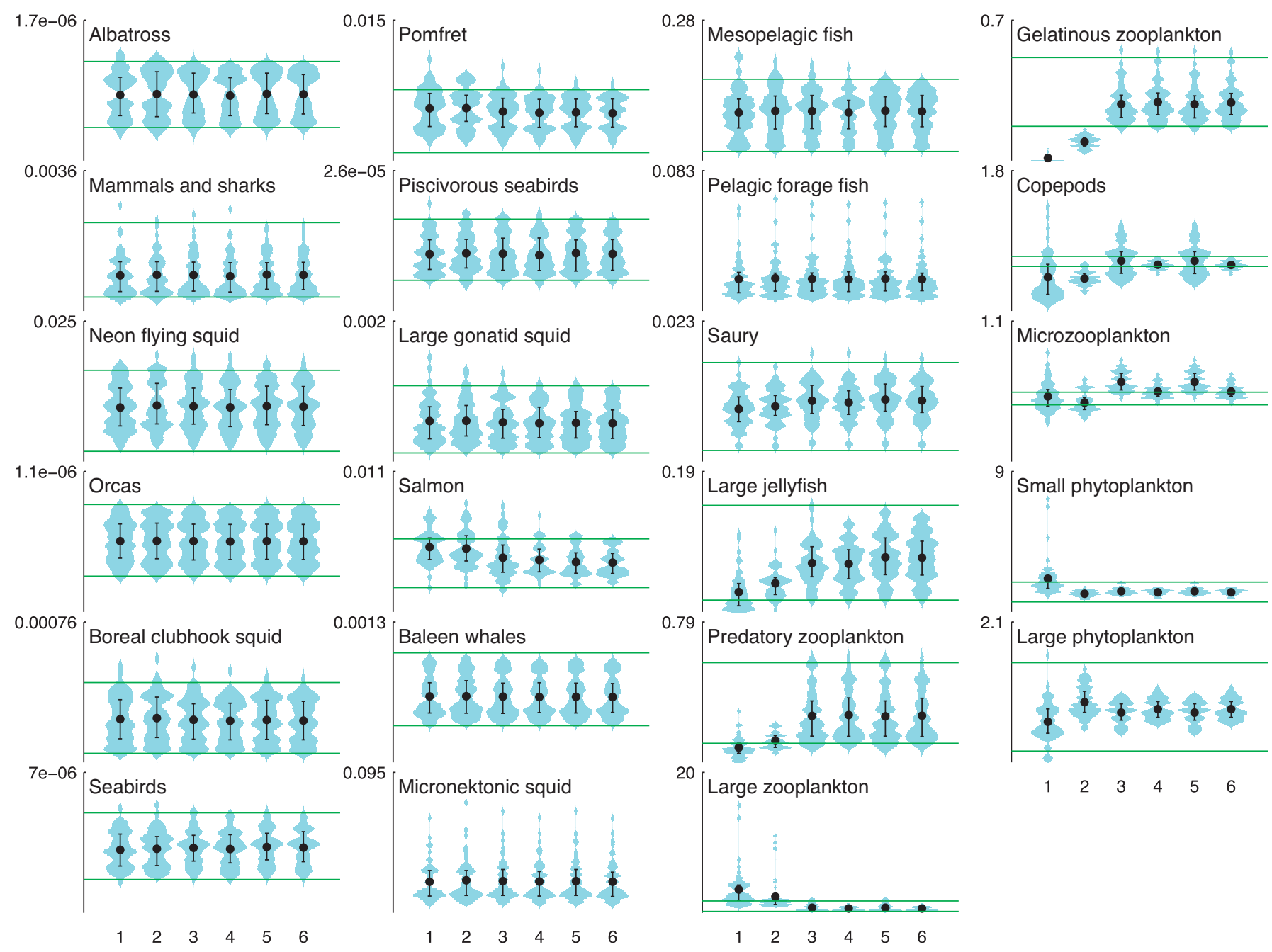

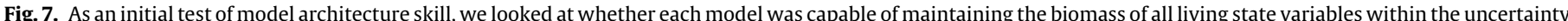

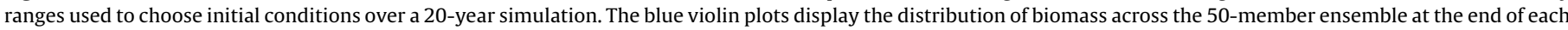

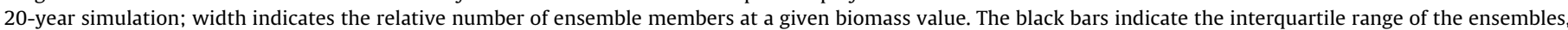

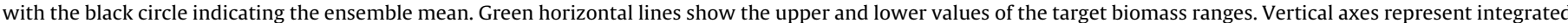
biomass, ranging from 0 to the labeled value, in $\mathrm{g} \mathrm{C} \mathrm{m}^{-2}$. The horizontal axis indicates the model architecture indices, which correspond to those found in Table 4 .

terms not linked to higher predators are indeed important factors to consider when modeling planktonic functional groups. The population dynamics of nektonic groups, on the other hand, were relatively unaffected by the switch between linear and quadratic mortality rates (Fig. 7, architectures 4 and 6).

We also found that the use of the quadratic mortality term could mask the inconsistencies in the mix of grazing functional responses used in the baseline scenario. Simply applying quadratic mortality to planktonic groups, and leaving the mix of functional responses (Fig. 7, architectures 3 and 5), could bring most ensemble members within the target ranges. However, the spread between ensemble members tended to be wider in this case, and a few simulations also created fall blooms under this architecture. Overall, the combination of a consistent predation functional response for all groups, as well as a quadratic mortality rate for all plankton groups, proved necessary to consistently reproduce both the target yearly averaged biomass values as well as the proper seasonal dynamics for lower trophic level groups. For simplicity, in our final architecture, we chose to use a quadratic mortality rate for nektonic groups as well; results using a linear mortality for nekton are similar.

\subsection{Validation of final model}

An ensemble of 50-year simulations was run to look more closely at the seasonal dynamics of the final model architecture over multi-decadal timescales. In this section we compare surface nutrient concentration, primary productivity, and functional group biomass of the simulations to a variety of measurements collected from the Eastern Subarctic Gyre region.

\subsubsection{Surface nutrients}

Ocean Station Papa is characterized by seasonal stratification, which plays a large role in controlling macronutrient concentrations in the surface ocean at this location. Increased winds and decreased surface temperatures lead to deep mixing in the winter months (November-February), with the mixed layer depth 


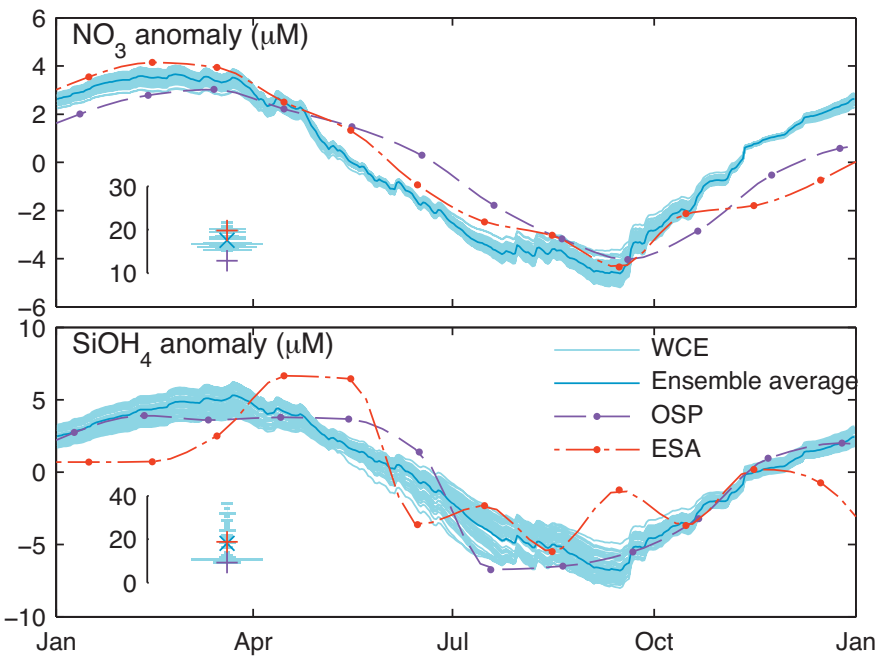

Fig. 8. Modeled surface nutrient anomaly from yearly average over one simulation year versus observations at Ocean Station Papa. Observations for Ocean Station Papa (OSP) reflect measurement at this location over the period of 1969-1981 (Whitney and Freeland, 1999). Also shown are the WOA05 climatological surface nitrate anomaly values averaged over the entire Eastern Subarctic Gyre (ESA) region (Garcia et al., 2006). Inset figures show the histograms of yearly averaged values at the end of the 50-year simulation period, along with the corresponding yearly average for each observation dataset.

reaching $90-120 \mathrm{~m}$ and allowing replenishment of nitrate and silicate to the mixed layer. In the summer, stratification increases and the mixed layer shoals to approximately $40 \mathrm{~m}$. The increased light levels along with plentiful macronutrients allow phytoplankton to bloom, leading to nutrient drawdown as the summer months progress. Typical nitrate drawdown, from peak winter level to lowest summer level, is $7 \mathrm{mmol} \mathrm{m}^{-3}$ nitrate and $10-11 \mathrm{mmol} \mathrm{m}^{-3}$ silicate. This region is a high nutrient, low chlorophyll region, with phytoplankton production primarily being limited by iron and light, so surface levels of nitrate and silicate remain high even during the summer (Whitney and Freeland, 1999; Harrison et al., 2004).

Maintaining surface nutrient concentrations consistent with observations requires both that the model properly replicates the seasonal deepening and shoaling of the mixed layer, and that it maintains the proper assemblages of phytoplankton. In particular, the seasonal changes in ratios between small phytoplankton that do not use silica, and diatoms (large phytoplankton) that do, will affect the relative drawdown of nitrate and silicic acid. Modeled nitrate drawdown in the WCE model ranges from 6.90 to

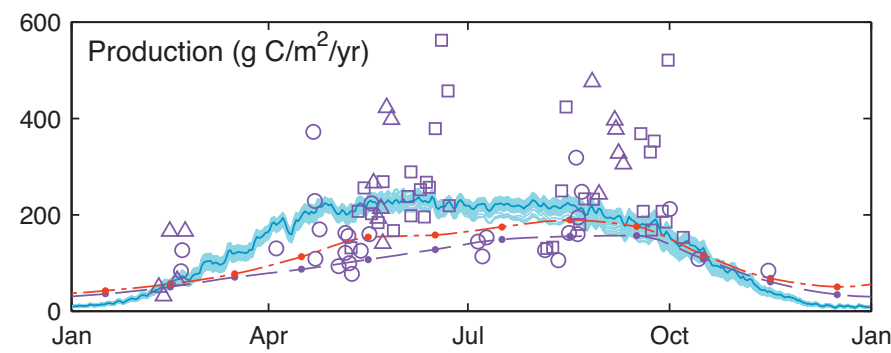

Fig. 9. Modeled net primary production over one simulation year. For comparison, net primary production values estimated by the Eppley-VGPM model applied to SeaWiFS data near Ocean Station Papa (purple dashed) and over the entire Eastern Subarctic Gyre (red dash-dot) are also shown, as well as measured production values at Ocean Station Papa as compiled by Boyd and Harrison (1999) (squares, circles, and triangles indicate data from three different studies, as described in Boyd and Harrison (1999, Fig. 7). (a) Biomass

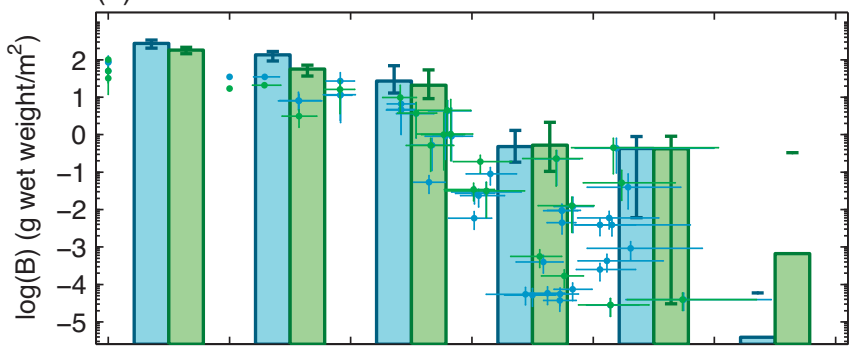

(b) Production/biomass

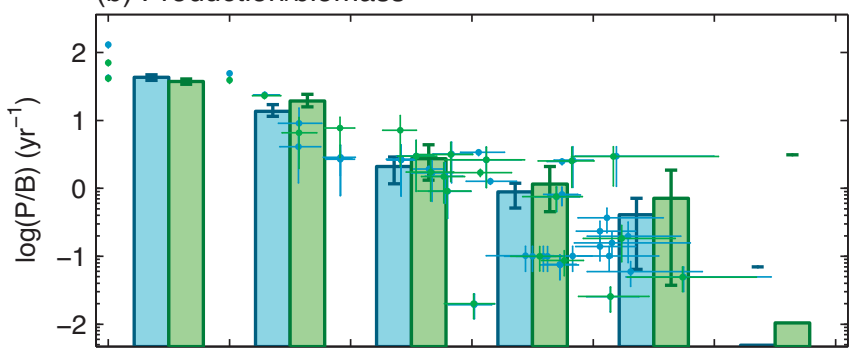

(c) Consumption/biomass

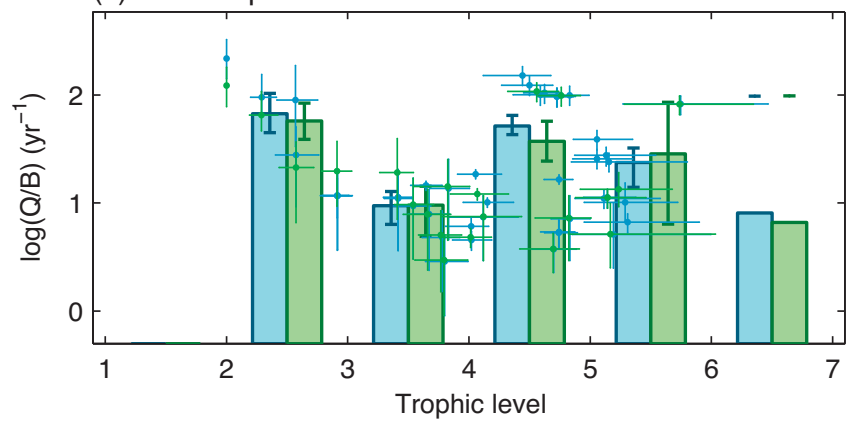

Fig. 10. Trophic diagnostics of the food web, for both the 48-group (blue) and the simplified 24-group (green) webs, including (a) biomass, (b) production per unit biomass, and (c) consumption per unit biomass. Bars indicate sum (biomass) or average (production and consumption) over each trophic level, while points show the values for each individual functional group. Error bars indicate the minimum and maximum values across 500 ensemble members.

$9.22 \mathrm{mmol} \mathrm{m}^{-3}$ over the ensemble members, with an average drawdown of $8.27 \mathrm{mmol} \mathrm{m}^{-3}$, and annually averaged surface nitrate levels stabilize at $14.90-21.84 \mathrm{mmol} \mathrm{m}^{-3}$, consistent with observations. Silicate drawdown varies more widely between ensemble members, from 8.78 to $13.83 \mathrm{mmol} \mathrm{m}^{-3}$, but the ensemble average of $12.17 \mathrm{mmol} \mathrm{m}^{-3}$ is very near the drawdown seen at Ocean Station Papa (Fig. 8). Surface concentrations of silica tended to drift a bit over the 50-year span of the simulations, reaching levels between 8.69 and $36.84 \mathrm{mmol} \mathrm{m}^{-3}$. However, because neither nitrate nor silicate serve as the limiting growth factor for phytoplankton, drifts in surface concentrations of either nutrient over the 50-year simulations did not affect the production level or standing stock of phytoplankton, and therefore did not lead to drift in any of the other state variables.

\subsubsection{Productivity}

Measurements of productivity at Ocean Station Papa have varied over time, from $60 \mathrm{~g} \mathrm{C} \mathrm{m}^{-2}$ year $^{-1}$ during the earlier sampling period from 1960 to $1976,140-170 \mathrm{~g} \mathrm{C} \mathrm{m}^{-2}$ year $^{-1}$ in studies conducted during the mid-1980's to early 1990s, to a higher summer value of $215 \mathrm{~g} \mathrm{C} \mathrm{m}^{-2}$ year $^{-1}$ during the JGOFS surveys of 1992-1997 


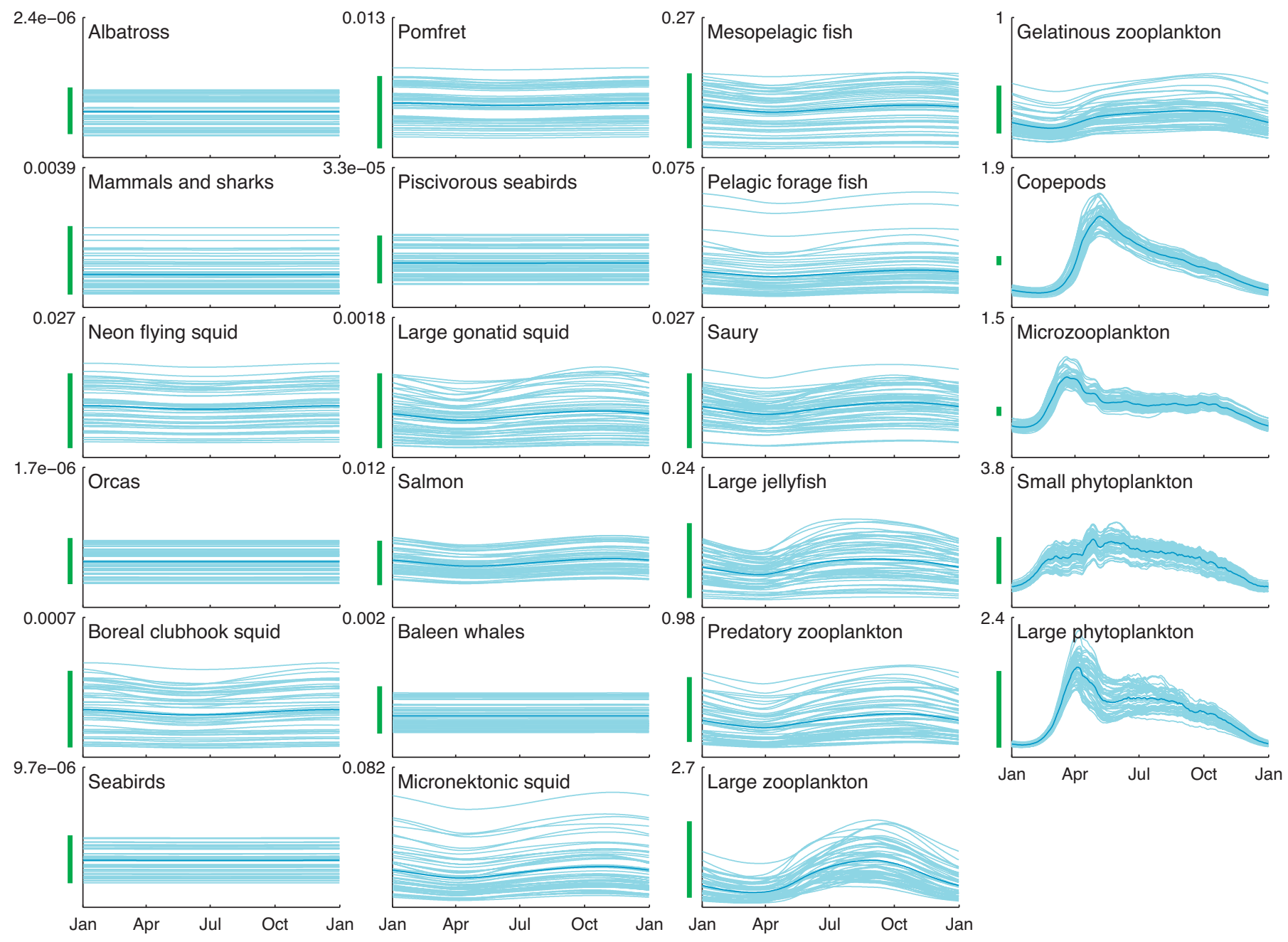

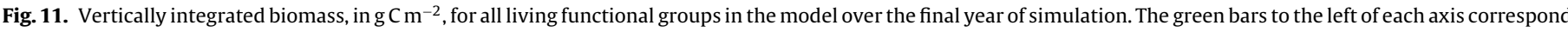

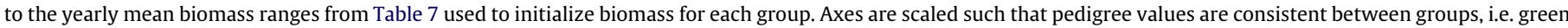
bars of equal length indicate equal uncertainty as a fraction of biomass; the lower limit of all axes is 0 .

(Harrison et al., 2004). There is debate regarding whether the range in values results from the development of more accurate clean sampling techniques for the later measurements (Fitzwater et al., 1982), or whether it (or some of it) reflects an actual change in productivity over this time period. Seasonally, observations show between a doubling and tripling of productivity between winter and summer (Boyd and Harrison, 1999). The modeled WCE productivity, with an annual average ranging between 122.04 and 145.8 and averaging $136.1 \mathrm{~g} \mathrm{C} \mathrm{m}^{-2}$ year $^{-1}$ over all ensemble members, falls within the range seen in observations. (Fig. 9).

\subsubsection{Trophic characteristics of the food web}

We subjected our ensemble of food webs to a series of diagnostic tests to verify the basic trophic characteristics of our food web against ecological theory (Link, 2010b). We ran these diagnostics on both the 48-group food web and the simplified 24-group food web in order to further confirm that our simplification process maintained the trophic structure of the Eastern Subarctic Gyre food web. We verified that biomass decreased by approximately six orders of magnitude across all trophic levels, following an approximate linear trend in logarithmic space, which reflects the expected size spectra distribution in a marine system. Vital rates of functional groups, including production and consumption per unit biomass, also generally decreased across trophic levels. Exceptions to the decreasing trend in consumption rates are seen in the three bird functional groups, and to a lesser extent the marine mammal groups; these groups occupy trophic levels near the top of the food web (4.5+) but due to their high metabolic requirements (in comparison with poikilothermic fish and squid groups) maintain consumption rates an order of magnitude higher than would be predicted by the linear trend (Fig. 10).

\subsubsection{Biomass of living groups}

As with the initial 20-year simulations, we considered the model successful at capturing upper trophic level dynamics if it was capable of maintaining yearly mean biomass levels within the initial uncertainty ranges over the entire simulation. Over all 50 ensemble members, only very small drifts out of this range were observed over the 50-year climatological simulation, indicating that this parameterization scheme is stable over decadal timescales (Fig. 11).

\section{Discussion}

In recent years, a large number of different modeling approaches have been applied to the end-to-end problem, and have been compared and contrasted in several reviews (Fulton, 2010; Travers et al., 2007). The complexity of these model frameworks and the processes they resolve cover a wide spectrum. In creating the water column ecosystem model, we intended to create a tool capable 
of analyzing ecosystem response to environmental perturbations at both the bottom and top of the food chain. The model presented here has a combination of strengths that make it valuable for diverse climate-ecosystem applications.

It provides a true two-way coupling between upper and lower trophic level species, nutrient cycling, and physics, allowing full analysis of the interacting effects of bottom-up climate effects and top-down predation and fisheries effects. The coupling includes both propagation of effects through the food web via predator-prey interactions, as well as direct feedback between all levels of the food chain and the physical and chemical environment.

The model maintains robust and stable population dynamics when run over decadal to centennial timescales. Natural climate variability often manifests itself with periods on the order of a decade, as quantified by indices such as ENSO or the PDO, while anthropogenic climate change studies often look $50-100$ years into the future. Therefore this model is suited for the study of such climate effects on population dynamics.

Finally, the intra-model ensemble approach used in this study allows us to simulate many potential manifestations of a single ecosystem that all fall within the uncertainty ranges of the observed data. When modeling complex food web interactions, a single representation of a food web is often not capable of capturing the full range of potential effects resulting from a change in the environment or a change in fishing pressure. Therefore, this ensemble method allows us to better quantify the uncertainty of the simulation results.

This model also provides an example for coupling multiple vertical spatial scales into a single model. In this particular case, using only one dimension, we were able to link lower trophic level functional groups that required a high spatial resolution with upper trophic level groups whose population dynamics could be resolved in a zero-dimensional physical space. The varying spatial scales allowed us to capture the necessary high-resolution variations in physical properties (such as light level, temperature, and stratification) that directly effect the locations and concentrations of smaller organisms without slowing down the upper trophic level calculations with an unnecessarily fine spatial grid.

The model architecture experiments discussed in Section 3.1 elucidated a number of important points regarding the coupling of plankton ecosystem models with fisheries food web models. The first point is that density-dependent mortality remains important for capturing the seasonal dynamics of planktonic organisms, even when the model fully resolves all predators of these planktonic groups. This is particularly true at the phytoplankton level, where a linear mortality rate allows blooms to grow well beyond the levels seen in observations in this region. The quadratic mortality term is likely encompassing a variety of processes not explicitly resolved by the process equations of this model. Phytoplankton aggregates, particularly of diatoms, are known to be a major contributor to sinking marine snow and occurs primarily when diatom concentrations are high (Thornton, 2002). In addition, recent research has shown that viruses can be important agents of mortality for phytoplankton, on the same order as loss due to predation, and that density-dependent viral infection rates play a key roll in limiting phytoplankton blooms (Brussaard, 2004, and references therein). At the zooplankton level, Ohman and Hirche (2001) observed density-dependent rates of copepod egg mortality uncorrelated with resource availability, which they attributed to egg cannibalism by conspecific and similarly sized zooplankton. The results of the architecture experiments provide further support that density-dependent mortality is not simply a closure term to represent higher-level predators, but rather incorporates a variety of important loss processes that control the seasonal dynamics of planktonic organisms.

The experiments also clarified the importance of using a consistent functional form for grazing/predation that incorporates the strengths of both lower- and upper-trophic level models, so as to capture both seasonal variations and long-term coexistence among functional groups. The functional groups included in this model operate across a wide range of time scales, with doubling times ranging from a few days to over a decade. The population dynamics of groups with high turnover rates, whose growth and mortality processes operate on a scale of less than a month, can be very sensitive to assumptions regarding prey functional responses (Gentleman et al., 2003; Fulton et al., 2003). Analysis of piscivorous feeding among pelagic and demersal Atlantic fishes (Moustahfid et al., 2010), and a sensitivity study of a full ecosystem model to changes in functional responses (Fulton et al., 2003) both indicated that marine ecosystem dynamics are better captured by classic Holling Types 2 and 3 responses than by a linear assumption, though Fulton et al. (2003) also suggested that further complexity in functional response formulation may add unnecessary data requirements to the parameterization process with little additional payoff. The foraging arena functional response used in this model incorporates key elements elucidated in these studies, allowing it to resolve predator/prey dynamics at both the bottom and top of the food web.

Although the model discussed here is tailored to the North Pacific Subarctic region, the basic framework used can be extended to almost any oceanic ecosystem. The NEMURO biogeochemical model uses a structure common to many lower trophic level models in use today, where a minimal number of phytoplankton and zooplankton groups interact with nutrient pools, sinking and nonsinking detrital pools, and bacteria through processes of uptake, grazing, death, sinking, decomposition and mineralization (Fasham et al., 1990). The widespread use of Ecopath with Ecosim has also led to an abundance of food web models spanning the globe; over 100 published food web models can be found on the EwE website (http://www.ecopath.org). The Ecopath algorithm is also very flexible in the level of ecosystem complexity modeled, such that a user can aggregate or disaggregate species as necessary to suit the purposes of a given study. While the parameterization process, including parameterization of the biogeochemical model and the construction of an Ecopath food web specific to a particular region, is not a simple task, we do believe that the water column ecosystem framework can be applied to many pelagic ecosystems throughout the global ocean.

Implementing the model globally for climate change applications would require additional consideration of fundamental ecological and physiological considerations which would allow the model to extrapolate into data poor regions and into the novel environments expected under changing climate conditions. The methodologies for coupling fisheries food web and planktonic food web models developed herein, however, are readily adaptable to end-to-end model applications spanning a range of spatiotemporal scales.

\section{Acknowledgements}

Primary funding for Kelly Kearney provided through NOAA's Nancy Foster Scholarship. This work was supported in part by BP and Ford Motor Company through the Carbon Mitigation Initiative at Princeton University. This report was prepared by Kelly Kearney under award NA17RJ2612 and NA08OAR4320752 from the National Oceanic and Atmospheric Administration, U.S. Department of Commerce. The statements, findings, conclusions, and recommendations are those of the authors and do not necessarily reflect the views of the National Oceanic and Atmospheric Administration, or the U.S. Department of Commerce. This work is partially supported through the Nippon Foundation Nereus Project. State estimates derived from the GECCO model were provided by the 
ECCO Consortium for Estimating the Circulation and Climate of the Ocean funded by the National Oceanographic Partnership Program (NOPP). We thank Eileen Kearney for creating the artwork used in the food web diagram. Finally, we thank two anonymous referees for their helpful comments in preparing the final version of this manuscript.

\section{Appendix A. The 1D physical model}

The physical model used in this study is a Matlab-based code designed to simulate a one-dimensional water column. The code is designed so that a variety of different biological models can be run within the same physical context, as was done in this study with the standalone NEMURO simulations and the fully coupled water column ecosystem simulations.

The mixed-layer model simulates the evolution of water column properties under specified forcing by wind, heat, and salinity forcing. Allowance is also made for currents via a depth-independent pressure acceleration. There are six physical state variables in the physical model formulation: $U$ and $V$ are the east to west and south to north current velocities, and $T$ and $S$ are the temperature and salinity. The turbulence closure scheme introduces the remaining two state variables: $q^{2}$ is a turbulent quantity equal to twice the turbulent kinetic energy, and $\ell$ is a turbulent length scale. These two state variables are used to calculate mixing-related parameters $\left(K_{M}\right.$ and $K_{V}$ ) in Eqs. (A.1)-(A.4).

The momentum equations are standard one-dimensional formulations:

$$
\begin{aligned}
& \frac{\partial U}{d t}-f V=-\frac{1}{\rho_{0}} \frac{\partial p}{\partial x}+\frac{\partial}{\partial z} K_{M} \frac{\partial U}{\partial z}-\epsilon U \\
& \frac{\partial V}{d t}+f U=-\frac{1}{\rho_{0}} \frac{\partial p}{\partial y}+\frac{\partial}{\partial z} K_{M} \frac{\partial V}{\partial z}-\epsilon V
\end{aligned}
$$

where $f$ is the Coriolis parameter, $\rho$ is the density, $K_{M}$ is the viscosity, $\frac{\partial p}{\partial x}$ is a specified pressure gradient (to impose a mean current) and $\epsilon$ is a momentum dissipation term. The dissipation term serves as a surrogate for horizontal momentum divergence. It removes energy from past storm events over a specified timescale as though energy was being transferred to more quiescent surrounding waters. Energy tends to accumulate unrealistically in one-dimensional water columns without this effect (Mellor, 2001). The value of $\epsilon$ was tuned such that the energy in the modeled currents is consistent with that observed. Values comparable to the time scales of storm events $\left(1 / 3\right.$ day $\left.^{-1}\right)$ yielded reasonable results. The equations are solved using a semi-implicit Crank-Nicolson scheme.

The Mellor-Yamada turbulence closure scheme (Mellor and Yamada, 1982) is used to calculate mixing coefficients. The reader is referred to this reference and Mellor (2004) for the governing equations and other details of this formulation. A $k$-epsilon formulation (see review by Umlauf and Burchard (2005)) was also tested and yielded similar results to those presented herein. The top and bottom boundary conditions for Eqs. (A.1) and (A.2) are provided by the wind stress formulation of Large and Pond (1981) and a quadratic bottom drag law, respectively. Mixing at the surface was augmented by the wave breaking scheme of Mellor and Blumberg (2004).

The temperature and salinity equations are given by:

$$
\begin{aligned}
& \frac{\partial T}{\partial t}=\frac{\partial}{\partial z} K_{V} \frac{\partial T}{\partial z}+s s \\
& \frac{\partial S}{\partial t}=\frac{\partial}{\partial z} K_{V} \frac{\partial S}{\partial z}+s s
\end{aligned}
$$

where $K_{V}$ is the vertical turbulent diffusion coefficient, and $s s$ is used to indicate sources minus sinks. The temperature source minus sink term (shortwave heat flux) and boundary conditions (longwave heat flux, sensible and latent heating and cooling) are described in Section 2.1.1 in this paper. The salinity source minus sink term derives from the relaxation to observations as described in Section 2.1.1.

Biological state variables are mixed, where applicable, following the same formulation as Eq. (A.3), with the source minus sink term representing any additional vertical movement; in the simulations described in this paper, this term was used to apply sinking velocities to the particulate state variables ( $P O N$ and Opal). The set of equations describing the remaining biological sources and sinks (Appendix B) is solved following the mixing calculations at each time step.

\section{Appendix B. Process equations for the WCE model}

The WCE model consists of 7 non-living state variables, and 3 classes of living state variables, coupled together by a set of ordinary differential equations. For simplicity, the following equations omit indicators of depth resolution. Eqs. B.1-B.5 represent phytoplankton, zooplankton, and nekton classes of variables, with the subscript $i$ indicating the index of a functional group to which it pertains. All phytoplankton groups are represented by three state variables: phytoplankton nitrogen $(P n)$, phytoplankton silica $(P s)$, and phytoplankton iron $(P f)$, while zooplankton and nekton groups consist of only nitrogen state variables.

$$
\begin{aligned}
& \frac{d P n_{i}}{d t}=G p p_{i}-\operatorname{Res}_{i}-E x_{i}-\sum_{j} \operatorname{Con}_{i j}-\text { Mor }_{i} \\
& \frac{d P s_{i}}{d t}=R_{\mathrm{Si}: \mathrm{N}} \cdot\left(G p p_{i}-\operatorname{Res}_{i}-E x_{i}-\sum_{j} \operatorname{Con}_{i j}-\mathrm{Mor}_{i}\right) \\
& \frac{d P f_{i}}{d t}=\frac{B_{\mathrm{Fe}, \mathrm{i}}}{B_{i}} \cdot\left(G p p_{i}-\operatorname{Res}_{i}-E x_{i}-\sum_{j} \operatorname{Con}_{i j}-\text { Mor }_{i}\right)+U f e_{i} \\
& \frac{d Z_{i}}{d t}=\sum_{k} \operatorname{Con}_{k i}-E g e_{i}-E x c_{i}-\sum_{j} \operatorname{Con}_{i j}-\text { Mor }_{i} \\
& \frac{d K_{i}}{d t}=\sum_{k} \operatorname{ConI}_{k i}-\int_{0}^{z_{\max }} \operatorname{Ege}_{i}-\int_{0}^{z_{\max }} \operatorname{Exc}_{i}-\sum_{j} \operatorname{ConI}_{i j}-\text { MorI }_{i}
\end{aligned}
$$

$$
\begin{aligned}
\frac{d\left(\mathrm{NO}_{3}\right)}{d t}= & \operatorname{Dec}_{\mathrm{NH}_{4}, \mathrm{NO}_{3}}+f\left(\sum_{i} \operatorname{Res}_{i}-\sum_{i} G p p_{i}\right) \\
\frac{d\left(\mathrm{NH}_{4}\right)}{d t}= & \operatorname{Dec}_{\mathrm{DON}, \mathrm{NH}_{4}}+\operatorname{Dec}_{\mathrm{PON}, \mathrm{NH}_{4}}+\sum_{i} \operatorname{Exc}_{i}-\operatorname{Dec}_{\mathrm{NH}_{4}, \mathrm{NO}_{3}} \\
& +(1-f)\left(\sum_{i} \operatorname{Res}_{i}-\sum_{i} G p p_{i}\right)
\end{aligned}
$$

$$
\frac{d(D O N)}{d t}=\operatorname{Dec}_{\mathrm{PON}, \mathrm{DON}}+\sum_{i} E x_{i}-\operatorname{Dec}_{\mathrm{DON}, \mathrm{NH}_{4}}
$$

$\frac{d(P O N)}{d t}=\sum_{i} M o r_{i}+\sum_{i} E g e_{i}-\operatorname{Dec}_{\mathrm{PON}, \mathrm{DON}}-\operatorname{Dec}_{\mathrm{PON}, \mathrm{NH}_{4}}$ 


$$
\begin{aligned}
\frac{d\left(\mathrm{SiOH}_{4}\right)}{d t}= & R_{\mathrm{Si}: \mathrm{N}} \cdot\left(\sum_{i=\mathrm{diatom}} \operatorname{Res}_{i}+\sum_{i=\mathrm{diatom}} E x_{i}-\sum_{i=\mathrm{diatom}} G p p_{i}\right) \\
& +\mathrm{Dec}_{{\mathrm{Opal}, \mathrm{SiOH}_{4}}} \\
\frac{d(\mathrm{Opal})}{d t}= & R_{\mathrm{Si}: \mathrm{N}}\left(\sum_{i=\text { diatom }} \text { Mor }_{i}+\sum_{i=\text { diatom }} \sum_{j} \operatorname{Con}_{i j}\right)-\operatorname{Dec}_{\mathrm{Opal}, \mathrm{SiOH}_{4}}
\end{aligned}
$$

$$
\begin{aligned}
\frac{d(\mathrm{Fe})}{d t}= & \sum_{i}\left(f_{\mathrm{rem}} \cdot \frac{B_{\mathrm{Fe}, i}}{B_{i}} \cdot\left(\operatorname{Res}_{i}+E x_{i}+\sum_{j} \operatorname{Con}_{i j}+\text { Mor }_{i}\right)\right. \\
& \left.-\frac{B_{\mathrm{Fe}, i}}{B_{i}} \cdot G p p_{i}-U f e_{i}\right)
\end{aligned}
$$

For names and descriptions of all variables used in the above set of equations, as well as the flux equations in the following section, please see Tables 5, 6-8.

\section{B.1. Nitrogen flux equations for living state variables}

\section{B.1.1. Gross primary production (Gpp)}

Gross primary production fluxes flow from the $\mathrm{NO}_{3}$ and $\mathrm{NH}_{4}$ variables to each phytoplankton group, following (Kishi et al., 2007), with the addition of iron limitation following Fiechter et al. (2009). The uptake of nitrogen is described by:

$G p p_{i}=V_{\max , i} \exp \left(K_{G p p, i} T\right) \cdot L_{\mathrm{nut}, i} \cdot L_{\mathrm{light}, i} \cdot B_{i}$

where $B_{i}$ is the nitrogen-based biomass of group $i$, resolved with depth.

\section{B.1.2. Respiration (Res)}

Respiration applies to all phytoplankton groups, and flows from the phytoplankton to the $\mathrm{NO}_{3}$ and $\mathrm{NH}_{4}$ groups following the same $f$-ratio as uptake via primary production:

$\operatorname{Res}_{i}=\operatorname{Res}_{0 i} \exp \left(K_{\text {res }, i} T\right) B_{i}$

\section{B.1.3. Extracellular excretion (Ex)}

Extracellular excretion applies to all phytoplankton groups, and flows from the phytoplankton to the DON group. Following Kishi et al. (2007), extracellular excretion is proportional to the flux due to gross primary production:

$E x_{i}=\gamma_{i} \cdot G p p_{i}$

\section{B.1.4. Consumption (Con)}

Predator/prey interactions between functional groups follow the Aydin version of the foraging arena functional response. The exact form of the functional response varies based on whether the predator and prey groups are planktonic or nektonic. For interactions between two planktonic groups, the flux is resolved with depth for both the predator and prey group, and the uptake rates are temperature-dependent:

$$
\begin{aligned}
\operatorname{Con}_{i j}= & \frac{Q^{\prime}{ }_{i j}}{\exp \left(K_{G r a, i} \cdot T_{\mathrm{avg}}\right)} \exp \left(K_{G r a, i} \cdot T\right)\left(\frac{X_{i j} \cdot\left(B_{j} / B_{j}^{\prime}\right)}{X_{i j}-1+\left(B_{j} B^{\prime}{ }_{j}\right)}\right) \\
& \times\left(\frac{D_{i j} \cdot\left(B_{i} / B^{\prime}{ }_{i}\right)^{\theta_{i j}}}{D_{i j}-1+\left(B_{i} / B^{\prime}{ }_{i}\right)^{\theta_{i j}}}\right)
\end{aligned}
$$

where here, the subscripts $i$ and $j$ represent the prey and predator groups, respectively. As described in Section 2.2.2, the biomass and consumption rate parameters are derived from the Ecopath mass balance: $Q^{\prime}=\frac{Q^{*}}{M L D}$ and $B^{\prime}=\frac{B^{*}}{M L D}$, where $Q^{*}$ and $B^{*}$ are the perarea mass-balanced quantities returned directly from Ecopath. The parameters $M L D$ and $T_{\text {avg }}$ describe the yearly averaged mixed layer depth and mixed layer temperature, respectively, as simulated by the one-dimensional physical model.

For interactions between two nektonic groups, the functional response follows the same form, but in units of biomass integrated over depth. Nektonic consumption does not vary with temperature.

$$
\operatorname{ConI}_{i j}=Q_{i j}^{*}\left(\frac{X_{i j} \cdot\left(\text { Bint }_{j} / B_{j}^{*}\right)}{X_{i j}-1+\left(\text { Bint }_{j} / B_{j}^{*}\right)}\right)\left(\frac{D_{i j} \cdot\left(\text { Bint }_{i} / B_{i}^{*}\right)^{\theta_{i j}}}{D_{i j}-1+\left(\text { Bint }_{i} / B_{i}^{*}\right)^{\theta_{i j}}}\right)
$$

When a nektonic group preys upon a planktonic group, the total flux is calculated in depth-integrated units. However, the loss on the plankton side is resolved with depth and distributed proportionally to the prey biomass at each depth, while the flow to the predator remains in depth-integrated units:

$$
\begin{aligned}
\operatorname{Con}_{i j}= & Q_{i j}^{*}\left(\frac{X_{i j} \cdot\left(\text { Bint }_{j} / B_{j}^{*}\right)}{X_{i j}-1+\left(\text { Bint }_{j} / B_{j}^{*}\right)}\right)\left(\frac{D_{i j} \cdot\left(\int_{0}^{z_{\max }} B_{i} d z / B_{i}^{*}\right)^{\theta_{i j}}}{D_{i j}-1+\left(\int_{0}^{z_{\max }} B_{i} d z / B_{i}^{*}\right)^{\theta_{i j}}}\right) \\
& \cdot \frac{1}{\Delta z} \cdot \frac{B_{i} \Delta z}{\int_{0}^{z_{\max }} B_{i} d z} \\
\operatorname{ConI}_{i j}= & Q_{i j}^{*}\left(\frac{X_{i j} \cdot\left(\text { Bint }_{j} / B_{j}^{*}\right)}{X_{i j}-1+\left(\text { Bint }_{j} / B_{j}^{*}\right)}\right)\left(\frac{D_{i j} \cdot\left(\text { Bint }_{i} / B_{i}^{*}\right)^{\theta_{i j}}}{D_{i j}-1+\left(\text { Bint }_{i} / B_{i}^{*}\right)^{\theta_{i j}}}\right)
\end{aligned}
$$

where ConI $=\int_{0}^{z_{\max }} \operatorname{Con} d z$.

\section{B.1.5. Excretion (Exc) and egestion (Ege)}

Egestion and excretion are proportional to the total consumption of prey by a predator. Egestion flows from the predator to the PON group, with the exception of egestion by microzooplankton, where egestion is split between the $P O N, D O N$, and $\mathrm{NH}_{4}$ groups. Excretion flows from the predator group to the $\mathrm{NH}_{4}$ group. All excretion and egestion by nektonic groups is assumed to take place in the surface layer:

$$
\begin{aligned}
& \operatorname{Ege}_{i}=G S_{i} \cdot\left(\sum_{k=\text { plank }} \operatorname{Con}_{k i}+\frac{\sum_{\ell=n e k} \operatorname{ConI}_{\ell i}}{\Delta z_{1}}\right) \quad z=1 \\
& \text { Ege }_{i}=G S_{i} \cdot \sum_{k} \operatorname{Con}_{k i} \quad z \neq 1
\end{aligned}
$$

$E x c_{i}=\left(1-G E_{i}-G S_{i}\right) \cdot\left(\sum_{k=\text { plank }} \operatorname{Con}_{k i}+\frac{\sum_{\ell=n e k} \operatorname{ConI}_{\ell i}}{\Delta z_{1}}\right)$ $z=1$

$$
E x c_{i}=\left(1-G E_{i}-G S_{i}\right) \cdot \sum_{k} \operatorname{Con}_{k i} \neq 1
$$




\section{B.1.6. Non-predatory mortality (Mor)}

Non-predatory mortality, e.g. loss to old age or disease, is modeled as a quadratic function of biomass. For planktonic groups, this flux is in units of mass per volume:

$\operatorname{Mor}_{i}=\left(\frac{M_{0 i}}{B_{i}^{\prime}}\right) \cdot B_{i}^{2}$

while for nektonic groups it is in units of mass per area:

$\operatorname{MorI}_{i}=\left(\frac{M_{0 i}}{B_{i}^{*}}\right) \cdot$ Bint $_{i}^{2}$

As with egestion and excretion by nektonic groups, nonpredatory mortality of nektonic groups is assumed to occur in the surface layer, such that in the surface layer,

$\operatorname{Mor}_{i}=\frac{\operatorname{MorI}_{i}}{\Delta z_{1}}$

when $i=$ nekton.

\section{B.2. Additional fluxes}

\section{B.2.1. Proportional-to-nitrogen fluxes of silica and iron}

The majority of fluxes between iron- and silica-based state variables occur in proportion to nitrogenous fluxes. Silica fluxes due to gross primary production (Gpp), extracellular excretion $(E x)$, and respiration (Res) between phytoplankton groups and $\mathrm{SiOH}_{4}$ occur in a constant proportion to the respective fluxes in nitrogen between phytoplankton groups and all dissolved nitrogen pools $\left(\mathrm{NO}_{3}, \mathrm{NH}_{4}\right.$, and DON). Similarly, fluxes due to non-predatory mortality (Mor) from phytoplankton groups to the PON group are accompanied by proportional fluxes of silica from the large phytoplankton to particulate opal group. Silica is assumed to be completely egested by phytoplankton grazers, so the proportional flux due to predator consumption (Con) of phytoplankton silica is routed entirely to the particulate opal group, rather than being split between predator, egestion, and excretion as is the case for nitrogenous consumption.
Iron fluxes between the two phytoplankton groups and the dissolved iron group also occur proportionally to nitrogen fluxes, though the ratio between the two elements varies over time (see Appendix B.2.2). However, only a fraction of the iron fluxes out of the phytoplankton groups ends up in the dissolved iron pool, with the remainder leaving the system.

\section{B.2.2. Luxury iron uptake (Ufe)}

In addition to the proportional-to-nitrogen uptake and loss of iron due to gross primary production, respiration, extracellular excretion, grazing loss, and natural mortality, phytoplankton can also gain and lose iron through a relaxation process following the model of Fiechter et al. (2009). This model allows phytoplankton to take up dissolved iron in order to adjust their internal $\mathrm{Fe}: \mathrm{C}$ ratios toward a value predicted by the ambient dissolved iron in the surrounding water. This additional uptake term accounts for the fact that iron uptake, unlike macronutrient uptake, is not necessarily a function of dissolved iron concentration, and that iron to carbon ratios within phytoplankton cells can vary widely over time depending on conditions. The luxury uptake in the WCE module is described by:

$U f e_{i}=\frac{R_{0 i}-R_{i}}{t_{\mathrm{Fe}, i}} \cdot B_{i} \cdot R_{\mathrm{C}: \mathrm{N}}$

\section{B.2.3. Decomposition (Dec)}

Decomposition fluxes follow the model of Kishi et al. (2007), with a decay rate related to temperature:

$\operatorname{Dec}_{i j}=V_{D e c, i j} \exp \left(K_{D e c, i j} T\right) \cdot B_{i}$

where the subscripts $i$ and $j$ represent the source and sink groups, respectively, and $B_{i}$ the concentration of the source group.

\section{B.3. Tables of parameters}

See Tables 5-8.

Table 5

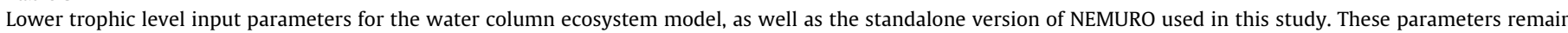
constant throughout a simulation.

\begin{tabular}{|c|c|c|c|}
\hline Parameter & Symbol & Group & Value \\
\hline \multicolumn{4}{|l|}{ Primary production } \\
\hline \multirow[t]{2}{*}{ Ammonium inhibition constant } & $\psi$ & PS & $1.5\left(\mathrm{mmol} \mathrm{N} \mathrm{m}^{-3}\right)^{-1}$ \\
\hline & & PL & $1.5\left(\mathrm{mmol} \mathrm{N} \mathrm{m}^{-3}\right)^{-1}$ \\
\hline \multirow[t]{2}{*}{ Half-saturation constant for ammonium } & $\mathrm{K}_{\mathrm{NH}_{4}}$ & PS & $0.1 \mathrm{mmol} \mathrm{N} \mathrm{m}^{-3}$ \\
\hline & $\mathrm{PL}$ & $0.3 \mathrm{mmol} \mathrm{N} \mathrm{m}^{-3}$ & \\
\hline \multirow[t]{2}{*}{ Half-saturation constant for nitrate } & $\mathrm{K}_{\mathrm{NH}_{3}}$ & PS & $1 \mathrm{mmol} \mathrm{N} \mathrm{m}^{-3}$ \\
\hline & PL & $3 \mathrm{mmol} \mathrm{N} \mathrm{m}^{-3}$ & \\
\hline Half-saturation constant for silica & $\mathrm{K}_{\mathrm{NSi}}$ & PL & $6 \mathrm{mmol} \mathrm{Si} \mathrm{m}^{-3}$ \\
\hline \multirow[t]{2}{*}{ Initial slope of $P-I$ curve } & $\alpha$ & PS & $0.017\left(\mathrm{~W} \mathrm{~m}^{-2}\right)^{-1} \mathrm{~d}^{-1}$ \\
\hline & PL & $0.016\left(\mathrm{~W} \mathrm{~m}^{-2}\right)^{-1} \mathrm{~d}^{-1}$ & \\
\hline Light dissipation coefficient of seawater & $\alpha_{1}$ & & $0.04 \mathrm{~m}^{-1}$ \\
\hline \multirow[t]{2}{*}{ Maximum uptake rate at $0^{\circ} \mathrm{C}$} & $V_{\max }$ & PS & $0.4 \mathrm{~d}^{-1}$ \\
\hline & & PL & $0.8 \mathrm{~d}^{-1}$ \\
\hline Phytoplankton self-shading coefficient & $\alpha_{2}$ & & $0.04 \mathrm{~m}^{-1}\left(\mathrm{mmol} \mathrm{N} \mathrm{m}^{-3}\right)^{-1}$ \\
\hline Silica to nitrogen ratio & $\mathrm{R}_{\mathrm{Si}: \mathrm{N}}$ & & $2 \mathrm{mmol} \mathrm{Si}(\mathrm{mmol} \mathrm{N})^{-1}$ \\
\hline Carbon to nitrogen ratio & $R_{\mathrm{CC}: \mathrm{N}}$ & & $6.625 \mathrm{~mol} \mathrm{C}(\mathrm{mol} \mathrm{N})^{-1}$ \\
\hline \multirow[t]{2}{*}{ Temperature coefficient for photosynthesis } & $K_{g p p}$ & PS & $0.0693\left({ }^{\circ} \mathrm{C}\right)^{-1}$ \\
\hline & & PL & $0.0693\left({ }^{\circ} \mathrm{C}\right)^{-1}$ \\
\hline \multirow[t]{2}{*}{ Empirical Fe:C function coefficient } & $b_{\mathrm{Fe}}$ & PS & $28.5\left(\mathrm{~mol} \mathrm{Cm}^{-3}\right)^{-1}$ \\
\hline & & PL & $42.6\left(\mathrm{~mol} \mathrm{Cm}^{-3}\right)^{-1}$ \\
\hline \multirow{2}{*}{ Empirical Fe:C function power } & $\alpha_{F e}$ & PS & 0.21 \\
\hline & & PL & 0.46 \\
\hline \multirow[t]{2}{*}{ Fraction of iron remineralized } & $f_{\text {rem }}$ & PS & 0.5 \\
\hline & & PL & 0.5 \\
\hline \multirow[t]{2}{*}{ Half-saturation constant for Fe:C } & $\mathrm{K}_{\mathrm{Fe}: \mathrm{C}}$ & PS & $12 \mu \mathrm{mol} \mathrm{Fe}(\mathrm{molC})^{-1}$ \\
\hline & & PL & $16.9 \mu \mathrm{mol} \mathrm{Fe}(\mathrm{mol} \mathrm{C})^{-1}$ \\
\hline \multirow[t]{2}{*}{ Timescale for iron uptake } & $\mathrm{t}_{\mathrm{Fe}}$ & PS & $1 \mathrm{~d}$ \\
\hline & & PL & $1 \mathrm{~d}$ \\
\hline
\end{tabular}


Table 5 (Continued)

\begin{tabular}{|c|c|c|c|}
\hline Parameter & Symbol & Group & Value \\
\hline \multicolumn{4}{|l|}{ Respiration } \\
\hline \multirow[t]{2}{*}{ Respiration rate at $0^{\circ} \mathrm{C}$} & $\operatorname{Res}_{0}$ & PS & $0.03 \mathrm{~d}^{-1}$ \\
\hline & & PL & $0.03 \mathrm{~d}^{-1}$ \\
\hline \multirow[t]{2}{*}{ Temperature coefficient for respiration } & $\mathrm{K}_{\text {Res }}$ & PS & $0.0519 \mathrm{~d}^{-1}$ \\
\hline & & PL & $0.0519 \mathrm{~d}^{-1}$ \\
\hline \multicolumn{4}{|l|}{ Extracellular excretion } \\
\hline \multirow[t]{2}{*}{ Ratio of extracellular excretion to photosynthesis } & $\gamma$ & PS & 0.135 \\
\hline & & PL & 0.135 \\
\hline \multicolumn{4}{|l|}{ Grazing } \\
\hline \multirow[t]{2}{*}{ Grazing inhibition coefficient } & $\psi_{\mathrm{gr}}$ & ZP on PL & $4.605\left(\mathrm{mmol} \mathrm{N} \mathrm{m}^{-3}\right)^{-1}$ \\
\hline & & ZP on ZS & $3.01\left(\mathrm{mmol} \mathrm{N} \mathrm{m}^{-3}\right)^{-1}$ \\
\hline \multirow[t]{7}{*}{ Grazing threshhold } & $B_{\text {thresh }}$ & ZS on PS & $0.04 \mathrm{mmol} \mathrm{N} \mathrm{m}^{-3}$ \\
\hline & & ZL on PS & $0.04 \mathrm{mmol} \mathrm{N} \mathrm{m}^{-3}$ \\
\hline & & ZL on PL & $0.04 \mathrm{mmol} \mathrm{N} \mathrm{m}^{-3}$ \\
\hline & & ZP on PL & $0.04 \mathrm{mmol} \mathrm{N} \mathrm{m}^{-3}$ \\
\hline & & ZL on ZS & $0.04 \mathrm{mmol} \mathrm{N} \mathrm{m}^{-3}$ \\
\hline & & $\mathrm{ZP}$ on $\mathrm{ZS}$ & $0.04 \mathrm{mmol} \mathrm{N} \mathrm{m}^{-3}$ \\
\hline & & ZP on ZL & $0.04 \mathrm{mmol} \mathrm{N} \mathrm{m}^{-3}$ \\
\hline \multirow[t]{3}{*}{ Ivlev constant } & $\lambda$ & ZS & $1.4\left(\mathrm{mmol} \mathrm{N} \mathrm{m}^{-3}\right)^{-1}$ \\
\hline & & ZL & $1.4\left(\mathrm{mmol} \mathrm{N} \mathrm{m}^{-3}\right)^{-1}$ \\
\hline & & $\mathrm{ZP}$ & $1.4\left(\mathrm{mmol} \mathrm{N} \mathrm{m}^{-3}\right)^{-1}$ \\
\hline \multirow[t]{7}{*}{ Maximum grazing rate at $0^{\circ} \mathrm{C}$} & $g_{\max }$ & ZS on PS & $0.8 \mathrm{~d}^{-1}$ \\
\hline & & ZL on PS & $0.1 \mathrm{~d}^{-1}$ \\
\hline & & ZL on PL & $0.4 d^{-1}$ \\
\hline & & $\mathrm{ZP}$ on $\mathrm{PL}$ & $0.2 \mathrm{~d}^{-1}$ \\
\hline & & ZL on ZS & $0.4 \mathrm{~d}^{-1}$ \\
\hline & & $\mathrm{ZP}$ on $\mathrm{ZS}$ & $0.2 \mathrm{~d}^{-1}$ \\
\hline & & ZP on ZL & $0.2 \mathrm{~d}^{-1}$ \\
\hline \multirow[t]{5}{*}{ Temperature coefficient for grazing } & $\mathrm{K}_{\mathrm{Gra}}$ & ZS & $0.0693\left({ }^{\circ} \mathrm{C}\right)^{-1}$ \\
\hline & & $\mathrm{ZL}$ & $0.0693\left({ }^{\circ} \mathrm{C}\right)^{-1}$ \\
\hline & & $\mathrm{ZP}$ & $0.0693\left({ }^{\circ} \mathrm{C}\right)^{-1}$ \\
\hline & & Gel. zoo. & $0.0693\left({ }^{\circ} \mathrm{C}\right)^{-1}$ \\
\hline & & Pred. zoo. & $0.0693\left({ }^{\circ} \mathrm{C}\right)^{-1}$ \\
\hline Mixed layer depth, annual average & $M L D$ & & $80 \mathrm{~m}$ \\
\hline Mixed layer temperature, annual average & $T_{\text {avg }}$ & & $8.26^{\circ} \mathrm{C}$ \\
\hline \multicolumn{4}{|l|}{ Egestion and excretion } \\
\hline \multirow[t]{3}{*}{ Assimilation efficiency } & $\alpha_{e g}$ & ZS & 0.7 \\
\hline & & $\mathrm{ZL}$ & 0.7 \\
\hline & & $\mathrm{ZP}$ & 0.7 \\
\hline \multirow[t]{3}{*}{ Growth efficiency } & $\beta_{\text {eg }}$ & ZS & 0.3 \\
\hline & & ZL & 0.3 \\
\hline & & $\mathrm{ZP}$ & 0.3 \\
\hline \multicolumn{4}{|l|}{ Decomposition } \\
\hline Decomposition (or nitrification) rate & $V_{D e c}$ & $\mathrm{NH}_{4}$ to $\mathrm{NO}_{3}$ & $0.03 \mathrm{~d}^{-1}$ \\
\hline & & $\mathrm{PON}$ to $\mathrm{NH}_{4}$ & $0.1 \mathrm{~d}^{-1}$ \\
\hline & & PON to DON & $0.1 \mathrm{~d}^{-1}$ \\
\hline & & DON to $\mathrm{NH}_{4}$ & $0.02 \mathrm{~d}^{-1}$ \\
\hline & & Opal to $\mathrm{SiOH}_{4}$ & $0.04 \mathrm{~d}^{-1}$ \\
\hline Temperature coefficient for decomposition & $\mathrm{K}_{\text {Dec }}$ & $\mathrm{NH}_{4}$ to $\mathrm{NO}_{3}$ & $0.0693\left({ }^{\circ} \mathrm{C}\right)^{-1}$ \\
\hline & & $\mathrm{PON}$ to $\mathrm{NH}_{4}$ & $0.0693\left({ }^{\circ} \mathrm{C}\right)^{-1}$ \\
\hline & & PON to DON & $0.0693\left({ }^{\circ} \mathrm{C}\right)^{-1}$ \\
\hline & & DON to $\mathrm{NH}_{4}$ & $0.0693\left({ }^{\circ} \mathrm{C}\right)^{-1}$ \\
\hline & & Opal to $\mathrm{SiOH}_{4}$ & $0.0693\left({ }^{\circ} \mathrm{C}\right)^{-1}$ \\
\hline Mortality & & & \\
\hline Mortality rate at $0^{\circ} \mathrm{C}$ & Mor $_{0}$ & PS & $0.0585 \mathrm{~d}^{-1}$ \\
\hline & & PL & $0.029 \mathrm{~d}^{-1}$ \\
\hline & & $\mathrm{ZS}$ & $0.0585 \mathrm{~d}^{-1}$ \\
\hline & & ZL & $0.0585 \mathrm{~d}^{-1}$ \\
\hline & & $\mathrm{ZP}$ & $0.0585 \mathrm{~d}^{-1}$ \\
\hline Temperature coefficient for mortality & $\mathrm{K}_{M o r}$ & PS & $0.0693\left({ }^{\circ} \mathrm{C}\right)^{-1}$ \\
\hline & & PL & $0.0693\left({ }^{\circ} \mathrm{C}\right)^{-1}$ \\
\hline & & ZS & $0.0693\left({ }^{\circ} \mathrm{C}\right)^{-1}$ \\
\hline & & $\mathrm{ZL}$ & $0.0693\left({ }^{\circ} \mathrm{C}\right)^{-1}$ \\
\hline & & $\mathrm{ZP}$ & $0.0693\left({ }^{\circ} \mathrm{C}\right)^{-1}$ \\
\hline
\end{tabular}


Table 6

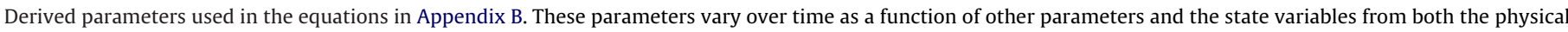
and biological models.

\begin{tabular}{|c|c|c|}
\hline Parameter name & Symbol & Definition \\
\hline Nitrogen limitation & $L_{N}$ & $\frac{\mathrm{NO}_{3}}{\mathrm{~K}_{\mathrm{NO}_{3}}+\mathrm{NO}_{3}} \cdot \exp \left(-\psi \mathrm{NH}_{4}\right)+\frac{\mathrm{NH}_{4}}{\mathrm{~K}_{\mathrm{NH}_{4}}+\mathrm{NH}_{4}}$ \\
\hline Silica limitation & $L_{\mathrm{Si}}$ & $\frac{\mathrm{SiOH}_{4}}{\mathrm{~K}_{\mathrm{SiOH}_{4}}+\mathrm{SiOH}_{4}}$ \\
\hline Iron limitation & $L_{\mathrm{Fe}}$ & $\frac{R_{\mathrm{Fe}: \mathrm{C}}^{2}}{\mathrm{~K}_{\mathrm{Fe}: \mathrm{C}^{2}+R_{\mathrm{Fe}: \mathrm{C}}^{2}}}$ \\
\hline$f$-ratio & $f$ & $\frac{\left(\mathrm{NO}_{3} / \mathrm{K}_{\mathrm{NO}_{3}}+\mathrm{NO}_{3}\right) \cdot \exp \left(-\psi \mathrm{NH}_{4}\right)}{\left(\mathrm{NO}_{3} /\left(\mathrm{K}_{\mathrm{NO}_{3}}+\mathrm{NO}_{3}\right)\right) \cdot \exp \left(-\psi \mathrm{NH}_{4}\right)+\left(\mathrm{NH}_{4} /\left(\mathrm{K}_{\mathrm{NH}_{4}}+\mathrm{NH}_{4}\right)\right)}$ \\
\hline Total nutrient limitation & $L_{\text {nut }}$ & $\min \left(L_{\mathrm{N}}, L_{\mathrm{Si}}, L_{\mathrm{Fe}}\right)$ \\
\hline Light limitation & $L_{\text {light }}$ & $1-\exp \left(\frac{\alpha I_{z}}{V_{\max }}\right)$ \\
\hline Empirical Fe:C ratio & $R_{0 i}$ & $b_{\mathrm{Fe}, \mathrm{i}} \mathrm{Fe}_{z}^{a_{\mathrm{Fe}, i}}$ \\
\hline Realized Fe:C ratio & $R_{i}$ & $\frac{B_{\mathrm{Fe}, \mathrm{i}}}{B_{i} \cdot R_{\mathrm{C}: \mathrm{N}}}$ \\
\hline
\end{tabular}

Table 7

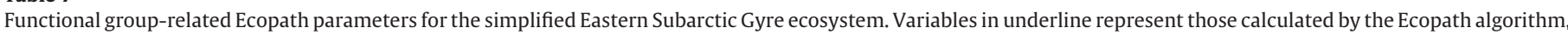

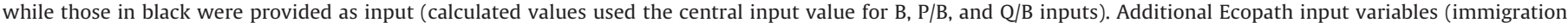
emigration, biomass accumulation, detrital import, fisheries catch, and fisheries discard) were all set to zero for the simulations used in this study.

\begin{tabular}{|c|c|c|c|c|c|c|c|c|c|}
\hline \multirow[t]{2}{*}{ Group } & \multicolumn{2}{|c|}{$\mathrm{B}\left(\mathrm{g} w \mathrm{w} \mathrm{m}^{-2}\right)$} & \multicolumn{2}{|c|}{ P/B $\left(\right.$ year $\left.^{-1}\right)$} & \multicolumn{2}{|c|}{$\mathrm{Q} / \mathrm{B}\left(\right.$ year $\left.^{-1}\right)$} & \multirow[t]{2}{*}{$\mathrm{EE}$} & \multirow[t]{2}{*}{ GE } & \multirow[t]{2}{*}{ GS } \\
\hline & Min & Max & Min & Max & Min & Max & & & \\
\hline Albatross & $2 \mathrm{E}-05$ & $6 \mathrm{E}-05$ & 0.03 & 0.07 & 65.272 & 97.908 & $\underline{0.05}$ & $6.128 \mathrm{E}-04$ & 0.2 \\
\hline Mammals and sharks & 0.018 & 0.113 & 0.082 & 0.286 & 9.185 & 19.199 & $\overline{0.003}$ & $\underline{0.013}$ & 0.2 \\
\hline Neon flying squid & 0.09 & 0.81 & 1.022 & 4.088 & 2.482 & 9.928 & $\overline{0.924}$ & $\overline{0.412}$ & 0.2 \\
\hline Orcas & $1.4 \mathrm{E}-05$ & $4.2 \mathrm{E}-05$ & 0.015 & 0.035 & 8.928 & 13.392 & $\overline{0 \mathrm{E}+00}$ & $\overline{0.002}$ & 0.2 \\
\hline Boreal clubhook squid & 0.002 & 0.022 & 1.022 & 4.088 & 2.92 & 11.68 & $\overline{0.207}$ & $\overline{0.35}$ & 0.2 \\
\hline Seabirds & $8.3 \mathrm{E}-05$ & $2.49 \mathrm{E}-04$ & 0.052 & 0.121 & 78.585 & 117.88 & $\overline{0.03}$ & $\overline{8} .77 \mathrm{E}-04$ & 0.2 \\
\hline Pomfret & 0.042 & 0.378 & 0.45 & 1.05 & \multicolumn{2}{|c|}{3.75} & $\overline{0.625}$ & 0.2 & 0.2 \\
\hline Piscivorous seabirds & $2.83 \mathrm{E}-04$ & $8.49 \mathrm{E}-04$ & 0.06 & 0.14 & 86.241 & 129.36 & 0.025 & $9.276 \mathrm{E}-04$ & 0.2 \\
\hline Large gonatid squid & 0.006 & 0.054 & 1.022 & 4.088 & 2.92 & 11.68 & $\overline{0.207}$ & 0.35 & 0.2 \\
\hline Salmon & 0.095 & 0.285 & 1.494 & 1.9 & 10.637 & 13.526 & $\overline{0.276}$ & $\overline{0.14}$ & 0.2 \\
\hline Baleen whales & 0.017 & 0.051 & 0.012 & 0.028 & 3.87 & 5.805 & $\overline{0.127}$ & $\overline{0.004}$ & 0.2 \\
\hline Micronektonic squid & \multicolumn{2}{|c|}{0.874} & 1.2 & 4.8 & 4.5 & 25.5 & 0.9 & 0.2 & 0.2 \\
\hline Mesopelagic fish & 0.9 & 8.1 & 0.36 & 1.44 & 0.9 & 5.1 & $\underline{0.163}$ & $\overline{0.3}$ & 0.2 \\
\hline Pelagic forage fish & \multicolumn{2}{|c|}{0.949} & 0.6 & 2.4 & 1.5 & 8.5 & 0.9 & $\overline{0.3}$ & 0.2 \\
\hline Saury & 0.09 & 0.81 & 0.64 & 2.56 & 2.37 & 13.43 & 0.592 & 0.203 & 0.2 \\
\hline Large jellyfish & 0.8 & 7.2 & 0.9 & 5.1 & 3 & 17 & $\overline{0 \mathrm{E}+00}$ & 0.3 & 0.2 \\
\hline Predatory zooplankton & 5.314 & 28.024 & 0.767 & 4.344 & 3.614 & 20.477 & $\overline{0.224}$ & $\overline{0.2} 12$ & 0.2 \\
\hline Large zooplankton & 9.229 & 83.059 & 3.256 & 10.698 & \multicolumn{2}{|c|}{8.517} & $\underline{0.562}$ & $\overline{0.3}$ & 0.3 \\
\hline Gelatinous zooplankton & 8.55 & 25.65 & 1.902 & 10.777 & 21.772 & 123.37 & 0.033 & 0.087 & 0.2 \\
\hline Copepods & 28.59 & 34.943 & 20.768 & 25.384 & \multicolumn{2}{|c|}{$\underline{79.083}$} & $\overline{0.874}$ & $\overline{0.3}$ & 0.3 \\
\hline Microzooplankton & 22.172 & 27.099 & 33.161 & 40.53 & \multicolumn{2}{|c|}{163.033} & $\overline{0.577}$ & 0.3 & 0.3 \\
\hline Small phytoplankton & 31.737 & 95.211 & 59.426 & 72.631 & & & $\underline{0.639}$ & & \\
\hline Large phytoplankton & 8.267 & 74.406 & 38.305 & 46.817 & & & $\overline{0.776}$ & & \\
\hline PON & 90 & 110 & & & & & & & \\
\hline
\end{tabular}

Table 8

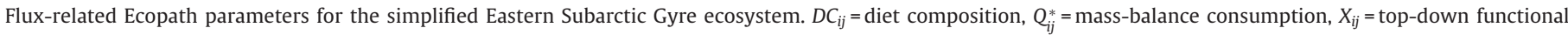
response parameter, and $D_{i j}=$ bottom-up function response parameter, where $i$ indicates the prey index and $j$ the predator index

\begin{tabular}{|c|c|c|c|c|c|c|c|c|c|c|c|}
\hline$i$ & $j$ & $D C_{i j}$ & $Q_{i j}^{*}$ & $X_{i j}$ & $D_{i j}$ & $i$ & $j$ & $D C_{i j}$ & $Q_{i j}^{*}$ & $X_{i j}$ & $D C_{i j}$ \\
\hline 3 & 1 & 0.686 & 0.0022 & 2 & 2 & 17 & 9 & 0.1133 & 0.0248 & 2 & 2 \\
\hline 5 & 1 & 0.0183 & 0.0001 & 2 & 2 & 18 & 9 & 0.31 & 0.0679 & 2 & 2 \\
\hline 9 & 1 & 0.0457 & 0.0001 & 2 & 2 & 20 & 9 & 0.2368 & 0.0519 & 2 & 2 \\
\hline 12 & 1 & 0.05 & 0.0002 & 2 & 2 & 12 & 10 & 0.078 & 0.1791 & 2 & 2 \\
\hline 14 & 1 & 0.1 & 0.0003 & 2 & 2 & 13 & 10 & 0.1069 & 0.2456 & 2 & 2 \\
\hline 15 & 1 & 0.1 & 0.0003 & 2 & 2 & 14 & 10 & 0.1069 & 0.2456 & 2 & 2 \\
\hline 3 & 2 & 0.2501 & 0.2323 & 2 & 2 & 17 & 10 & 0.0051 & 0.0118 & 2 & 2 \\
\hline 5 & 2 & 0.0067 & 0.0062 & 2 & 2 & 18 & 10 & 0.4681 & 1.0751 & 2 & 2 \\
\hline 7 & 2 & 0.1055 & 0.098 & 2 & 2 & 19 & 10 & 0.1317 & 0.3024 & 2 & 2 \\
\hline 9 & 2 & 0.0167 & 0.0155 & 2 & 2 & 20 & 10 & 0.1033 & 0.2372 & 2 & 2 \\
\hline 10 & 2 & 0.0953 & 0.0886 & 2 & 2 & 3 & 11 & 0.0229 & 0.0037 & 2 & 2 \\
\hline 12 & 2 & 0.134 & 0.1245 & 2 & 2 & 5 & 11 & 0.0006 & 0.0001 & 2 & 2 \\
\hline 13 & 2 & 0.0502 & 0.0466 & 2 & 2 & 7 & 11 & 0.0029 & 0.0005 & 2 & 2 \\
\hline 14 & 2 & 0.1154 & 0.1072 & 2 & 2 & 9 & 11 & 0.0015 & 0.0002 & 2 & 2 \\
\hline 15 & 2 & 0.2261 & 0.21 & 2 & 2 & 10 & 11 & 0.0026 & 0.0004 & 2 & 2 \\
\hline 3 & 3 & 0.295 & 0.8237 & 2 & 2 & 12 & 11 & 0.025 & 0.0041 & 2 & 2 \\
\hline 12 & 3 & 0.223 & 0.6227 & 2 & 2 & 13 & 11 & 0.0625 & 0.0102 & 2 & 2 \\
\hline 13 & 3 & 0.105 & 0.2932 & 2 & 2 & 14 & 11 & 0.076 & 0.0124 & 2 & 2 \\
\hline 14 & 3 & 0.319 & 0.8907 & 2 & 2 & 15 & 11 & 0.0063 & 0.001 & 2 & 2 \\
\hline 15 & 3 & 0.058 & 0.162 & 2 & 2 & 17 & 11 & 0.1373 & 0.0224 & 2 & 2 \\
\hline 1 & 4 & 0.0003 & $9.9994 \mathrm{E}-08$ & 2 & 2 & 18 & 11 & 0.3757 & 0.0614 & 2 & 2 \\
\hline 2 & 4 & 0.1184 & 0 & 2 & 2 & 20 & 11 & 0.287 & 0.0469 & 2 & 2 \\
\hline
\end{tabular}


Table 8 (Continued)

\begin{tabular}{|c|c|c|c|c|c|c|c|c|c|c|c|}
\hline$i$ & $j$ & $D C_{i j}$ & $Q_{i j}^{*}$ & $X_{i j}$ & $D_{i j}$ & $i$ & $j$ & $D C_{i j}$ & $Q_{i j}^{*}$ & $X_{i j}$ & $D C_{i j}$ \\
\hline 3 & 4 & 0.0457 & 0 & 2 & 2 & 12 & 12 & 0.05 & 0.6555 & 2 & 2 \\
\hline 5 & 4 & 0.0012 & $3.8123 \mathrm{E}-07$ & 2 & 2 & 17 & 12 & 0.163 & 2.1372 & 2 & 2 \\
\hline 6 & 4 & 0.0014 & $4.2497 \mathrm{E}-07$ & 2 & 2 & 18 & 12 & 0.4462 & 5.8492 & 2 & 2 \\
\hline 7 & 4 & 0.0583 & 0 & 2 & 2 & 20 & 12 & 0.3408 & 4.4681 & 2 & 2 \\
\hline 8 & 4 & 0.0046 & $1.4405 \mathrm{E}-06$ & 2 & 2 & 17 & 13 & 0.21 & 2.835 & 2 & 2 \\
\hline 9 & 4 & 0.0031 & $9.5306 \mathrm{E}-07$ & 2 & 2 & 18 & 13 & 0.442 & 5.967 & 2 & 2 \\
\hline 10 & 4 & 0.0528 & 0 & 2 & 2 & 20 & 13 & 0.348 & 4.698 & 2 & 2 \\
\hline 11 & 4 & 0.2754 & 0.0001 & 2 & 2 & 17 & 14 & 0.1716 & 0.8142 & 2 & 2 \\
\hline 12 & 4 & 0.05 & 0 & 2 & 2 & 18 & 14 & 0.4697 & 2.2285 & 2 & 2 \\
\hline 14 & 4 & 0.264 & 0.0001 & 2 & 2 & 20 & 14 & 0.3588 & 1.7023 & 2 & 2 \\
\hline 15 & 4 & 0.125 & 0 & 2 & 2 & 17 & 15 & 0.1338 & 0.4757 & 2 & 2 \\
\hline 12 & 5 & 0.99 & 0.0867 & 2 & 2 & 18 & 15 & 0.3662 & 1.3018 & 2 & 2 \\
\hline 14 & 5 & 0.01 & 0.0009 & 2 & 2 & 20 & 15 & 0.5 & 1.7775 & 2 & 2 \\
\hline 12 & 6 & 0.428 & 0.007 & 2 & 2 & 17 & 16 & 0.0798 & 3.1912 & 2 & 2 \\
\hline 14 & 6 & 0.2949 & 0.0048 & 2 & 2 & 18 & 16 & 0.2184 & 8.734 & 2 & 2 \\
\hline 15 & 6 & 0.2771 & 0.0045 & 2 & 2 & 19 & 16 & 0.0819 & 3.274 & 2 & 2 \\
\hline 12 & 7 & 0.75 & 0.5906 & 2 & 2 & 20 & 16 & 0.62 & 24.8 & 2 & 2 \\
\hline 13 & 7 & 0.08 & 0.063 & 2 & 2 & 18 & 17 & 0.2 & 40.153 & 2 & 2 \\
\hline 15 & 7 & 0.04 & 0.0315 & 2 & 2 & 20 & 17 & 0.8 & 160.62 & 2 & 2 \\
\hline 17 & 7 & 0.03 & 0.0236 & 2 & 2 & 20 & 18 & 0.55 & 219.79 & 10 & 27.04 \\
\hline 18 & 7 & 0.09 & 0.0709 & 2 & 2 & 21 & 18 & 0.205 & 219.79 & 10 & 27.04 \\
\hline 20 & 7 & 0.01 & 0.0079 & 2 & 2 & 23 & 18 & 0.245 & 109.9 & 10 & 6.1116 \\
\hline 12 & 8 & 0.2816 & 0.0172 & 2 & 2 & 20 & 19 & 0.25 & 310.25 & 2 & 2 \\
\hline 14 & 8 & 0.277 & 0.0169 & 2 & 2 & 21 & 19 & 0.25 & 310.25 & 2 & 2 \\
\hline 15 & 8 & 0.277 & 0.0169 & 2 & 2 & 23 & 19 & 0.5 & 620.5 & 2 & 2 \\
\hline 18 & 8 & 0.0932 & 0.0057 & 2 & 2 & 21 & 20 & 0.217 & 1175.3 & 10 & 7.7258 \\
\hline 20 & 8 & 0.0712 & 0.0043 & 2 & 2 & 22 & 20 & 0.212 & 1175.3 & 10 & 1.9315 \\
\hline 12 & 9 & 0.33 & 0.0723 & 2 & 2 & 23 & 20 & 0.571 & 1567 & 10 & 5.7944 \\
\hline 14 & 9 & 0.01 & 0.0022 & 2 & 2 & 22 & 21 & 1 & 8163.2 & 10 & 2.2344 \\
\hline
\end{tabular}

\section{References}

Aita, M.N., Yamanaka, Y., Kishi, M.J., 2007. Interdecadal variation of the lower trophic ecosystem in the northern Pacific between 1948 and 2002, in a 3-D implementation of the NEMURO model. Ecological Modelling 202, 81-94.

Aydin, K., Gaichas, S., Ortiz, I., Kinzey, D., Friday, N., 2007. A comparison of the Bering Sea, Gulf of Alaska, and Aleutian Islands Large marine ecosystems through food web modeling. NOAA Technical Memorandum.

Aydin, K.Y., McFarlane, G.A., King, J.R., Megrey, B.A., 2003. The BASS/MODEL report on trophic models of the Subarctic Pacific Basin ecosystems. PICES Scientific Report 25.

Aydin, K.Y., McFarlane, G.A., King, J.R., Megrey, B.A., Myers, K.W., 2005. Linking oceanic food webs to coastal production and growth rates of Pacific salmon (Oncorhynchus spp.), using models on three scales. Deep Sea Research Part II 53, 757-780.

Beamish, R.J., Bouillon, D.R., 1993. Pacific salmon production trends in relation to climate. Canadian Journal of Fisheries and Aquatic Sciences 50, 1002-1016.

Boyd, P., Harrison, P.J., 1999. Phytoplankton dynamics in the NE subarctic Pacific. Deep Sea Research Part II 46, 2405-2432.

Brodeur, R., McKinnell, S., Nagasawa, K., Pearcy, W., Radchenko, V., Takagi, S., 1999. Epipelagic nekton of the North Pacific subarctic and Transition Zones. Progress in Oceanography 43, 365-397.

Brodeur, R.D., Ware, D.M., 1992. Long-term variability in zooplankton biomass in the subarctic Pacific Ocean. Fisheries Oceanography 1, 32-38.

Brussaard, C., 2004. Viral Control of Phytoplankton Populations - a Review. Journal of Eukaryotic Microbiology 51, 125-138.

Christensen, V., Walters, C.J., 2004. Ecopath with Ecosim: methods, capabilities and limitations. Ecological Modelling 172, 109-139.

Denman, K.L., Brasseur, G., Chidthaisong, A., Ciais, P., Cox, P.M., Dickinson, R.E., Hauglustaine, D., Heinze, C., Holland, E., Jacob, D., et al., 2007. Couplings between changes in the climate system and biogeochemistry. In: Solomon, S., et al. (Eds.), Climate Change 2007: The Physical Science Basis. Contribution of Working Group I to the Fourth Assessment Report of the Intergovernmental Panel on Climate Change. Cambridge University Press, Cambridge, United Kingdom and New York, NY, USA.

Denman, K.L., Miyake, M., 1973. Upper layer modification at Ocean Station Papa: observations and simulation. Journal of Physical Oceanography 3, 185-196.

Denman, K.L., Pena, M.A., 1999. A coupled 1-D biological/physical model of the northeast subarctic Pacific Ocean with iron limitation. Deep Sea Research Part II 46 , 2877-2908.

Eslinger, D.L., Kashiwai, M.B., Kishi, M.J., Megrey, B.A., Ware, D.M., Werner, F.E., 2000. MODEL Task Team Workshop Report-Final report of the international Workshop to develop a prototype lower trophic level model for comparison of different marine ecosystems in the North pacific. PICES Scientific report 15

Fasham, M.J.R., Ducklow, H.W., McKelvie, S.M., 1990. A nitrogen-based model of plankton dynamics in the oceanic mixed layer. Journal of Marine Research 48, 591-639.

Fiechter, J., Moore, A.M., Edwards, C.a., Bruland, K.W., Di Lorenzo, E., Lewis, C.V.W., Powell, T.M., Curchitser, E.N., Hedstrom, K., 2009. Modeling iron limitation of primary production in the coastal Gulf of Alaska. Deep Sea Research Part II 56 2503-2519.

Fitzwater, S.E., Knauer, G.A., Martin, J.H., 1982. Metal contamination and its effect on primary production measurements. Limnology and Oceanography, 544-551.

Francis, R.C., Hare, S.R., Hollowed, A.B., Wooster, W.S., 1998. Effects of interdecadal climate variability on the oceanic ecosystems of the NE Pacific. Fisheries Oceanography 7, 1-21.

Friehe, C.A., Schmitt, K.F., 1976. Parameterization of air-sea interface fluxes of sensible heat and moisture by the bulk aerodynamic formulas. Journal of Physical Oceanography 6, 801-809.

Fujii, M., Yamanaka, Y., Nojiri, Y., Kishi, M.J., Chai, F., 2007. Comparison of seasonal characteristics in biogeochemistry among the subarctic North Pacific stations described with a NEMURO-based marine ecosystem model. Ecological Modelling 202, 52-67.

Fulton, E.A., 2010. Approaches to end-to-end ecosystem models. Journal of Marine Systems 81, 171-183.

Fulton, E.a., Parslow, J.S., Smith, A.D., Johnson, C.R., 2004. Biogeochemical marine ecosystem models II: the effect of physiological detail on model performance. Ecological Modelling 173, 371-406.

Fulton, E.a., Smith, A.D., Johnson, C.R., 2003. Mortality and predation in ecosystem models: is it important how these are expressed? Ecological Modelling 169, 157-178.

Fulton, E.a., Smith, A.D., Johnson, C.R., 2004. Biogeochemical marine ecosystem models I: IGBEM- a model of marine bay ecosystems. Ecological Modelling 174, 267-307.

Garcia, H.E., Locarnini, R.A., Boyer, T.P., Antonov, J.I., 2006. World Ocean Atlas 2005. Vol. 4, Nutrients (Phosphate, Nitrate, Silicate). NOAA Atlas NESDIS 64, National Oceanic and Atmospheric Administration. U.S. Government Printing Office, Washington, DC.

Gentleman, W., Leising, A., Frost, B., Strom, S., Murray, J., 2003. Functional responses for zooplankton feeding on multiple resources: a review of assumptions and biological dynamics. Deep Sea Research Part II 50, 2847-2875.

Hansen, P.J., Bjornsen, P.K., Hansen, B.W., 1997. Zooplankton grazing and growth: scaling within the $2-2000 \mu \mathrm{m}$ body size range. Limnology and Oceanography 42, 687-704.

Harrison, P.J., Whitney, F.a., Tsuda, A., Saito, H., Tadokoro, K., 2004. Nutrient and Plankton Dynamics in the NE and NW Gyres of the Subarctic Pacific Ocean. Journal of Oceanography 60, 93-117.

Keyl, F., Wolff, M., 2008. Environmental variability and fisheries: what can models do? Reviews in Fish Biology Fisheries 18, 273-299.

Kishi, M.J., Ito, S., Megrey, B.A., Rose, K.A., Werner, F.E., 2010. A review of the NEMURO and NEMURO. FISH models and their application to marine ecosystem investigations. Journal of Oceanography, 1-14.

Kishi, M.J., Kashiwai, M., Ware, D.M., Megrey, B.A., Eslinger, D.L., Werner, F.E. Noguchiaita, M., Azumaya, T., Fujii, M., Hashimoto, S., Noguchi-Aita, M., Others, 2007. NEMURO - a lower trophic level model for the North Pacific marine ecosystem. Ecological Modelling 202, 12-25.

Large, W.G., Pond, S., 1981. Open ocean momentum flux measurements in moderate to strong winds. Journal of Physical Oceanography 11, 324-336. 
Large, W.G., Yeager, S.G., 2009. The global climatology of an interannually varying air-sea flux data set. Climate Dynamics 33, 341-364.

Lehodey, P., Senina, I., Murtugudde, R., 2008. A spatial ecosystem and populations dynamics model (SEAPODYM)-modeling of tuna and tuna-like populations. Progress in Oceanography 78, 304-318.

Link, J., 2010. Ecosystem-based Fisheries Management: Confronting Tradeoffs. Cambridge University Press.

Link, J.S., 2010b. Adding rigor to ecological network models by evaluating a set of prebalance diagnostics: a plea for PREBAL. Ecological Modelling 221, 1580-1591.

Mantua, N.J., Hare, S.R., Zhang, Y., Wallace, J.M., Francis, R.C., 1997. A Pacific interdecadal climate oscillation with impacts on salmon production. Bulletin of the American Meteorological Society 78, 1069-1079.

Maury, O., 2010. An overview of APECOSM, a spatialized mass balanced “Apex Predators ECOSystem Model" to study physiologically structured tuna population dynamics in their ecosystem. Progress Oceanography 84, 113-117.

Megrey, B.A., Rose, K.A., Klumb, R.A., Hay, D.E., Werner, F.E., Eslinger, D.L., Smith, S.L., 2007. A bioenergetics-based population dynamics model of Pacific herring (Clupea harengus pallasi) coupled to a lower trophic level nutrient-phytoplankton-zooplankton model: description, calibration, and sensitivity analysis. Ecological Modelling 202, 144-164.

Mellor, G., Blumberg, A., 2004. Wave breaking and ocean surface layer thermal response. Journal of Physical Oceanography 34, 693-698.

Mellor, G.L., 2001. One-dimensional, ocean surface layer modeling: a problem and a solution. Journal of Physical Oceanography 31, 790-809.

Mellor, G.L., 2004. User's Guide for a Three-Dimensional, Primitive Equation, Numerical Ocean Model. Atmospheric and Oceanic Sciences Program, Princeton University.

Mellor, G.L., Yamada, T., 1982. Development of a turbulence closure model for geophysical fluid problems. Reviews of Geophysics Space Geophysics 20, 851-875.

Moustahfid, H., Tyrrell, M.C., Link, J.S., Nye, J.A., Smith, B.E., Gamble, R.J., 2010. Functional feeding responses of piscivorous fishes from the northeast US continental shelf. Oecologia 163, 1059-1067.

Nagata, T., 2000. Production mechanisms of dissolved organic matter. In: Kirchman, D.L. (Ed.), Microbial Ecology of the Oceans. John Wiley and Sons, Inc., New York, pp. 121-152.

Ohman, M.D., Hirche, H.J., 2001. Density-dependent mortality in an oceanic copepod population. Nature 412, 638-641.

Plaganyi, E.E., 2007. Models for an ecosystem approach to fisheries. FAO Fisheries Technical Paper 477, 108.

Platt, T., Jassby, A.D., 1976. The relationship between photosynthesis and light for natural assemblages of coastal marine phytoplankton. Journal of Phycology 12, 421-430.

Polovina, J.J., 1984. Model of a Coral Reef Ecosystem I. The ECOPATH Model and its applications to French Frigate Shoals. Coral Reefs 3, 1-11.
Polovina, J.J., Mitchum-i, G.T., Evansd, T., Mitchum, G.T., Evans, G.T., 1995. Decada and basin-scale variation in mixed layer depth and the impact on biologica production in the Central and North Pacific, 1960-88. Deep Sea Research 42, 1701-1716.

Ricker, W., 1954. Stock and recruitment. Journal of the Fisheries Research Board of Canada 11, 559-623.

Simpson, J.J., Paulson, C.A., 1979. Mid-ocean observations of atmospheric radiation. Quarterly Journal of the Royal Meteorological Society 105, 487-502.

Steele, J., Henderson, E., 1981. A simple plankton model. American Naturalist 117, 676-691.

Steele, J.H., 1962. Environmental control of photosynthesis in the sea. Limnology Oceanography 7, 137-150.

Stock, C.a., Alexander, M.a., Bond, N.a., Brander, K.M., Cheung, W.W.L., Curchitser E.N., Delworth, T.L., Dunne, J.P. Griffies, S.M., Haltuch, M.a., Hare, J.A., Hollowed, A.B., Lehodey, P., Levin, S.A., Link, J.S., Rose, K.A., Rykaczewski, R.R., Sarmiento, J.L., Stouffer, R.J., Schwing, F.B., Vecchi, G.A., Werner, F.E., 2011. On the use of IPCC-class models to assess the impact of climate on Living Marine Resources. Progress Oceanography 88, 1-27.

Thornton, D., 2002. Diatom aggregation in the sea: mechanisms and ecological implications. European Journal of Phycology 37, 149-161.

Travers, M., Shin, Y.J.J., Jennings, S., Cury, P., 2007. Towards end-to-end models for investigating the effects of climate and fishing in marine ecosystems. Progress Oceanography $75,751-770$.

Umlauf, L., Burchard, H., 2005. Second-order turbulence closure models for geophysical boundary layers. A review of recent work. Continental Shelf Research 25, 795-827.

Van Cappellen, P., Dixit, S., van Beusekom, J., 2002. Biogenic silica dissolution in the oceans: Reconciling experimental and field-based dissolution rates. Global Biogeochemical Cycles 16, 1075.

Walters, C., Christensen, V., Pauly, D., 1997. Structuring dynamic models of exploited ecosystems from trophic mass-balance assessments. Reviews in Fish Biology and Fisheries 7, 139-172.

Werner, F.E., Ito, S.I., Megrey, B.A., Kishi, M.J., 2007. Synthesis of the NEMURO model studies and future directions of marine ecosystem modeling. Ecological Modelling 202, 211-223.

Whitney, F.A., Freeland, H.J., 1999. Variability in upper-ocean water properties in the NE Pacific Ocean. Deep Sea Research Part II 46, 2351-2370.

Wong, C., Waser, N., Nojiri, Y., Johnson, W., Whitney, F., Page, J., Zeng, J., 2002. Seasonal and interannual variability in the distribution of surface nutrients and dissolved inorganic carbon in the Northern North Pacific: influence of El Nino. Journal of Oceanography 58, 227-243.

Yoshie, N., Yamanaka, Y., Rose, K.A., Eslinger, D.L., Ware, D.M., Kishi, M.J., 2007. Parameter sensitivity study of the NEMURO lower trophic level marine ecosystem model. Ecological Modelling 202, 26-37. 